\title{
3D electrical conductivity tomography of volcanoes
}

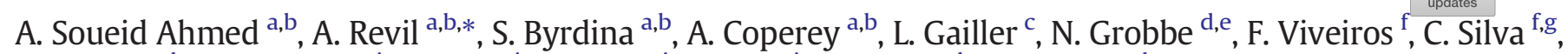
D. Jougnot ${ }^{\mathrm{h}}$, A. Ghorbani ${ }^{\mathrm{i}}$, C. Hogg ${ }^{\mathrm{j}}$, D. Kiyan ${ }^{\mathrm{j}}$, V. Rath ${ }^{\mathrm{j}}$, M.J. Heap ${ }^{\mathrm{k}}$, H. Grandis ${ }^{1}$, H. Humaida ${ }^{\mathrm{m}}$

a Université Grenoble Alpes, CNRS, IRD, IFSTTAR, ISTerre, Grenoble, France

b Université Savoie Mont Blanc, ISTerre, Chambéry, France

c Université Blaise Pascal - Clermont-Ferrand II, Clermont-Ferrand, France

${ }^{\mathrm{d}}$ Hawai'i Institute of Geophysics and Planetology, School of Ocean and Earth Science and Technology, University of Hawai'i at Mānoa, Honolulu, HI, USA

e Water Resources Research Center, University of Hawai'i at Mānoa, Honolulu, HI, USA

${ }^{\mathrm{f}}$ Instituto de Investigação em Vulcanologia e Avaliação de Riscos, Universidade dos Açores, Ponta Delgada, Portugal

${ }^{g}$ Centro de Informação e Vigilância Sismovulcânica dos Açores, Ponta Delgada, Portugal

h Sorbonne Universités, UPMC Univ. Paris 06, CNRS, EPHE, UMR 7619 METIS, Paris, France

i Department of Mining and Metallurgical Engineering, Yazd University, Yazd, Iran

j Geophysics Section, School of Cosmic Physics, Dublin Institute for Advanced Studies, 5 Merrion Square, Dublin 2, Ireland

k Géophysique Expérimentale, Institut de Physique de Globe de Strasbourg, UMR 7516 CNRS, Université de Strasbourg/EOST, Strasbourg cedex, France

${ }^{1}$ Applied and Exploration Geophysics Group, Faculty of Mining and Petroleum Engineering, Institut Teknologi Bandung (ITB), Bandung, Indonesia

${ }^{m}$ Center for Volcanology and Geological Hazard Mitigation, Geological Agency of Indonesia, Indonesia

\section{A R T I C L E I N F O}

\section{Article history:}

Received 30 December 2017

Received in revised form 28 February 2018

Accepted 16 March 2018

Available online 21 March 2018

\begin{abstract}
A B S T R A C T
Electrical conductivity tomography is a well-established galvanometric method for imaging the subsurface electrical conductivity distribution. We characterize the conductivity distribution of a set of volcanic structures that are different in terms of activity and morphology. For that purpose, we developed a large-scale inversion code named ECT-3D aimed at handling complex topographical effects like those encountered in volcanic areas. In addition, ECT-3D offers the possibility of using as input data the two components of the electrical field recorded at independent stations. Without prior information, a Gauss-Newton method with roughness constraints is used to solve the inverse problem. The roughening operator used to impose constraints is computed on unstructured tetrahedral elements to map complex geometries. We first benchmark ECT-3D on two synthetic tests. A first test using the topography of Mt. St Helens volcano (Washington, USA) demonstrates that we can successfully reconstruct the electrical conductivity field of an edifice marked by a strong topography and strong variations in the resistivity distribution. A second case study is used to demonstrate the versatility of the code in using the two components of the electrical field recorded on independent stations along the ground surface. Then, we apply our code to real data sets recorded at (i) a thermally active area of Yellowstone caldera (Wyoming, USA), (ii) a monogenetic dome on Furnas volcano (the Azores, Portugal), and (iii) the upper portion of the caldera of Kilauea (Hawai'i, USA). The tomographies reveal some of the major structures of these volcanoes as well as identifying alteration associated with high surface conductivities. We also review the petrophysics underlying the interpretation of the electrical conductivity of fresh and altered volcanic rocks and molten rocks to show that electrical conductivity tomography cannot be used as a stand-alone technique due to the non-uniqueness in interpreting electrical conductivity tomograms. That said, new experimental data provide evidence regarding the strong role of alteration in the vicinity of preferential fluid flow paths including magmatic conduits and hydrothermal vents.
\end{abstract}

(c) 2018 Elsevier B.V. All rights reserved.

\footnotetext{
* Corresponding author.

E-mail addresses: abdellahi.soueid-ahmed@univ-smb.fr (A. Soueid Ahmed) andre.revil@univ-smb.fr (A. Revil), svetlana.byrdina@univ-smb.fr (S. Byrdina), L.Gailler@opgc.univ-bpclermont.fr (L. Gailler), ngrobbe@higp.hawaii.edu (N. Grobbe), Maria.FB.Viveiros@azores.gov.pt (F. Viveiros), Catarina.PP.Silva@azores.gov.pt (C. Silva), damien.jougnot@upmc.fr (D. Jougnot), aghorbani@yazd.ac.ir (A. Ghorbani), chogg@cp.dias.ie (C. Hogg), duygu@cp.dias.ie (D. Kiyan), vrath@cp.dias.ie (V. Rath), heap@unistra.fr (M.J. Heap), grandis@geoph.itb.ac.id (H. Grandis).
}

\section{Introduction}

Electrical conductivity tomography has proven to be an effective geophysical method for imaging the shallow subsurface structures. Nowadays, its use is well-established for a variety of applications in geosciences, including environmental applications such as contaminant plume mapping and remediation monitoring (e.g., Naudet et al., 2004; Goes and Meekes, 2004; Müller et al., 2010), the characterization of shallow aquifers in hydrogeology (e.g., Binley et al., 2002; Koestel et 
al., 2009), geotechnical applications (e.g., Sudha et al., 2009; Oyeyemi and Olofinnade, 2016), and biogeophysical applications (e.g., Al Hagrey, 2007). In practice, performing an electrical conductivity survey is simple. It consists of injecting an electrical current between two injection electrodes ( $A$ and $B$ ) and recording the resulting electrical potential difference between two potential electrodes ( $M$ and $N$ ) or a network of electrodes. With recently-developed systems such as the FullWaver instrument from IRIS (http://www.iris-instruments.com/v-fullwaver. html), we can also measure the two components of the electrical field along the ground surface (the normal component being equal to zero) on remote stations making electrical conductivity tomography feasible at large scales.

The recorded electrical potential difference data are generally transformed into resistance or apparent electrical conductivity/resistivity data and then inverted using an inverse scheme to obtain an image of the electrical resistivity field of the subsurface. The depth of investigation of electrical conductivity tomography depends on the nature of the medium, the electrode spacing, the intensity of the injected current and the electrode configuration. With long cables a depth of investigation of $600 \mathrm{~m}$ can easily be obtained. With decentralized systems, a depth of a few kilometers can be reached with a $10 \mathrm{~kW}$ generator and enough distance between the receivers. Electrode distances $>100 \mathrm{~m}$ have also been used in a number of studies on geothermal systems (Jardani et al., 2008). Storz et al. (2000) performed a DC resistivity survey down to $4 \mathrm{~km}$ in Germany. This makes galvanometric DC conductivity a complementary tool with respect to electromagnetic methods (such as magnetotellurics and time-domain electromagnetic methods) used in volcanology (e.g., Manzella et al., 2004; Troiano et al., 2009; Usui et al., 2016).

Electrical conductivity is very sensitive to the composition and temperature of volcanic rocks, such as if they are molten or solidified and potentially altered. Therefore, knowing the electrical resistivity can help identifying the structures, connectivity, and fluids migration in the hydrothermal systems of active volcanoes. In fact, fluids with a high temperature and salinity increase the electrical conductivity of the host rock. Alteration of volcanic rocks is produced by the circulation of hydrothermal fluids involving the replacement of primary igneous glass and minerals (such as amphibole, plagioclase, and pyroxene,) by secondary minerals (e.g., Bonnet and Corriveau, 2007). We are especially interested in the case where these secondary minerals are clay minerals such as kaolinite, chlorite, illite, and smectite (Honnorez et al., 1998). Alteration of the surrounding materials can create conductive bodies. Volcanic edifices exhibit high conductivity anomalies that are characteristic of the presence of hydrothermal fluids and alteration. This high conductivity contrast allows for delineating the hydrothermal system.

While electrical conductivity tomography is a simple and efficient technique, few works have been carried out to image volcanic edifices. Revil et al. (2010) were the first to perform a true 3D electrical resistivity of an active volcano (Vulcano, Italy) while previous 3D interpolation of 1D inverted data (Nicollin et al., 2006) were criticized by Linde and Revil (2007) as producing unphysical results. Revil et al. (2010) imaged a conductive body associated with the localization of temperature and $\mathrm{CO}_{2}$ anomalies at the ground surface. This conductive feature was identified as the main part of the hydrothermal system. Byrdina et al. (2017) imaged the main structures of the hydrothermal system of Merapi volcano (Indonesia) by combining electrical conductivity tomography, self-potential and $\mathrm{CO}_{2}$ flux data. They highlighted the presence of conductive bodies (around $20 \mathrm{Ohm} \mathrm{m}$ ) showing sharp resistivity contrasts with the andesite lava flows (up to $100,000 \mathrm{Ohm} \mathrm{m}$ ). The conductive anomalies have been considered to be part of the probably interconnected hydrothermal body of Merapi volcano. Rosas-Carbajal et al. (2016) collected a large data set (23,000 measurements) during a set of electrical conductivity tomography surveys aimed at reconstructing a 3D electrical conductivity model of a small dome called La Soufrière de Guadeloupe (Guadeloupe Island, Lesser Antilles, Caribbean). They combined the information inferred from their 3D electrical conductivity model together with geological and geochemical data to assess the influence of the circulation of hot fluids on potential collapse hazards in these volcanic edifices. Gresse et al. (2017) performed a 3D resistivity tomography of Solfatara volcano in Italy. They identified some high conductive areas associated to the hydrothermal system. Fikos et al. (2012) carried out a 2D electrical conductivity tomography of the hydrothermal system of the Taal volcano in the Philippines and various papers have been published regarding $2 \mathrm{D}$ electrical resistivity surveys on volcanoes including monogenetic domes (e.g., Finizola et al., 2006, 2010, BardeCabusson et al., 2013, just to cite few examples).

From a numerical point of view, some difficulties may arise when dealing with electrical conductivity tomography in volcanic areas. In short, we are interested in developing a code that can handle complex
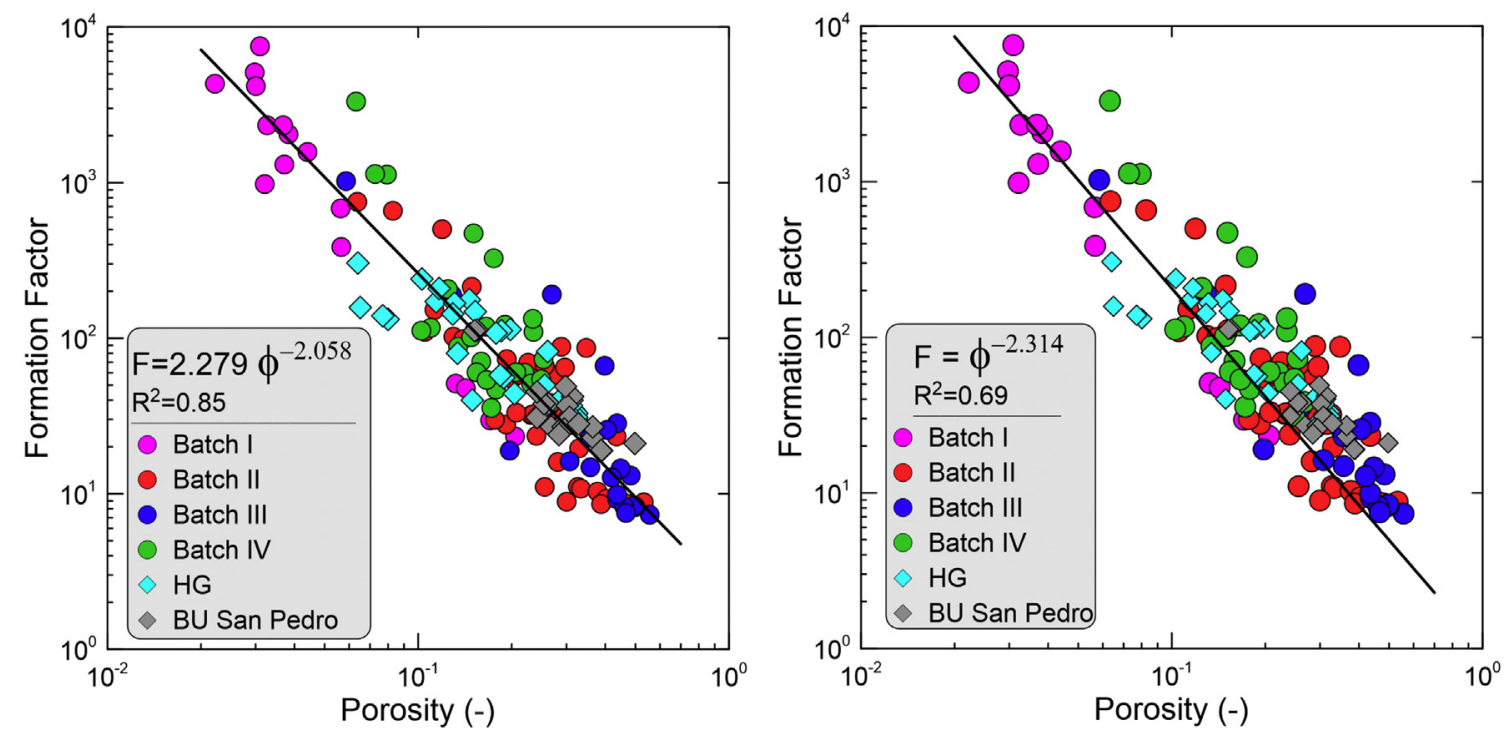

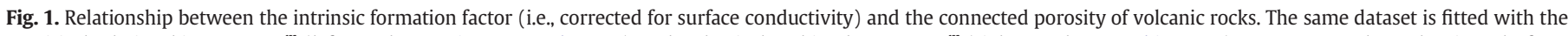

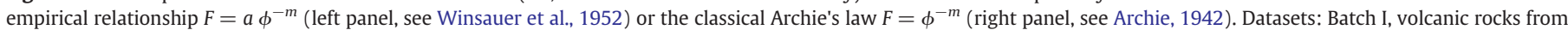

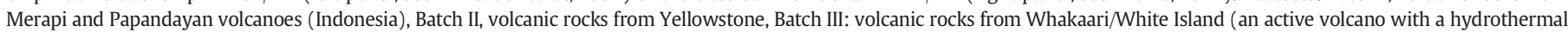

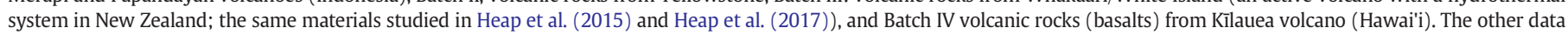
(HG and San Pedro) are volcaniclastic materials from Revil et al. (2002). 


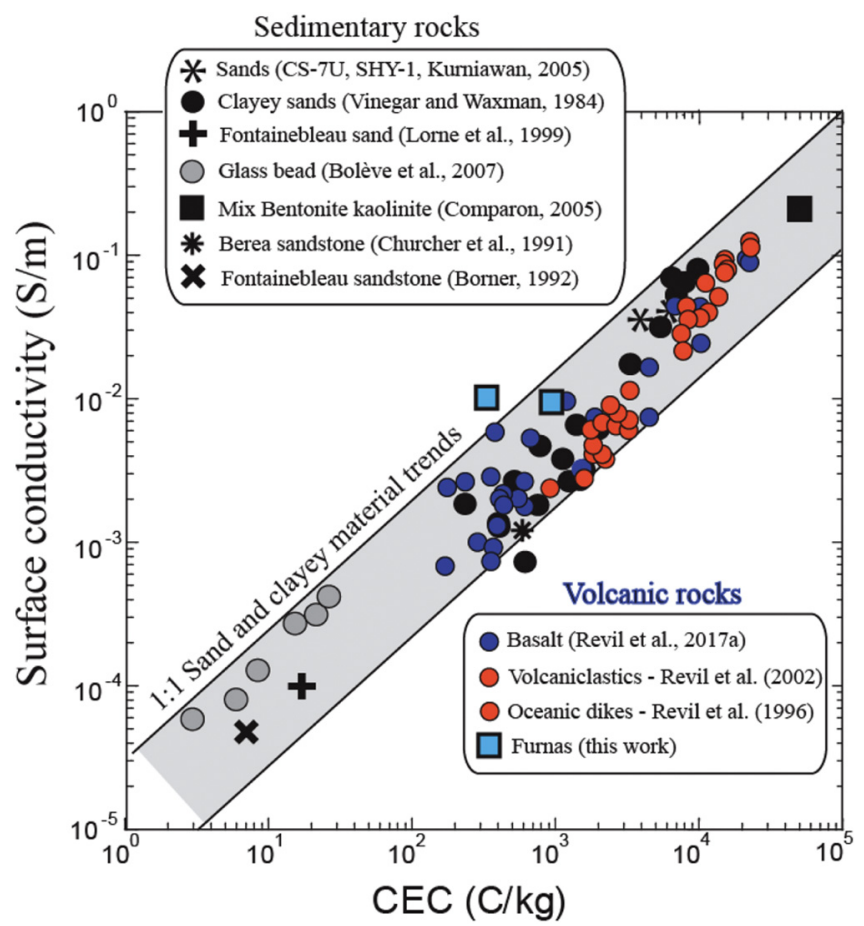

Fig. 2. Surface conductivity of volcanic rocks $\sigma_{S}\left(\right.$ in $\mathrm{S} \mathrm{m}^{-1}$ ) versus cation exchange capacity (in $\mathrm{C} \mathrm{kg}^{-1}$ ). We compare here the results from sedimentary rocks and volcanic rocks. The volcanic rocks include those from Revil et al. (2017), the volcaniclastic materials from Revil et al. (2002), and the oceanic dike samples studied by Revil et al. (1996) (normalized by the tortuosity). The data from the literature are from Bolève et al. (2007, glass beads, $\mathrm{NaCl}$ ), Vinegar and Waxman (1984, shaly sands, $\mathrm{NaCl}$ ), Churcher et al. (1991) (CEC for the Berea sandstone), Lorne et al. (1999, Fontainebleau sand $\mathrm{KCl}$ ), Kurniawan (2005, clean sand, Sample CS-7U, porosity 0.1234 , CEC $=4088 \mathrm{C} \mathrm{kg}^{-1}$ ), Börner (1992, sample F3 Fontainebleau sandstone, porosity of 0.068 , surface conductivity of $6.6 \times 10^{-5} \mathrm{~S} \mathrm{~m}^{-1}$, estimated CEC from the grain diameter, see Revil, 2013, CEC of $5.80 \mathrm{C} \mathrm{kg}^{-3}$ ), and Comparon (2005, mixtures of MX80 bentonite and kaolinite, porosity of 0.40 , estimated

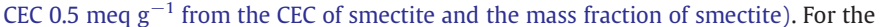
two samples from Furnas (Azores Islands), the equilibrium pH values are 4.6 and 6.2.

topographies and that can be used to invert the two components of the electrical field as well. First, accounting for the sharp topography of some volcanic edifices is often necessary to obtain reliable resistivity tomograms. This implies the need for a precise meshing of the ground surface based on digital elevation maps. This can be performed with the help of unstructured grids. This comes with the cost however of significantly increasing the number of cells, making the electrical conductivity inverse problem severely underdetermined. This also leads to the assembly and inversion of large ill-conditioned matrices that need to be handled during the inversion. Finally, when the number of measurements is high, the computational effort needed for solving the forward problem is large and therefore the use of high performance computing techniques is necessary.

Very few works have been done in 3D electrical resistivity/conductivity imaging of volcanic structures with the galvanometric technique. Johnson et al. (2010) developed an electrical conductivity tomography code and benchmarked it on different case studies (e.g., Revil et al., 2010). Günther et al. (2006) developed BERT for inverting electrical resistivity data on arbitrary geometries. In the present work, our aim is to characterize through electrical imaging some parts of the hydrothermal systems of three volcanic systems. A thermally-active area of the Yellowstone caldera (Wyoming, USA), a monogenetic dome on Furnas Volcano (the Azores, Portugal), and the caldera of the Kîlauea volcano (Hawai'i, USA). These three sites have been considered because they correspond to different scales of investigation with various levels of alteration and active / inactive hydrothermal systems. We have obtained core samples from these three sites to determine the effect of surface conductivity on the overall conductivity measured by electrical conductivity tomography.

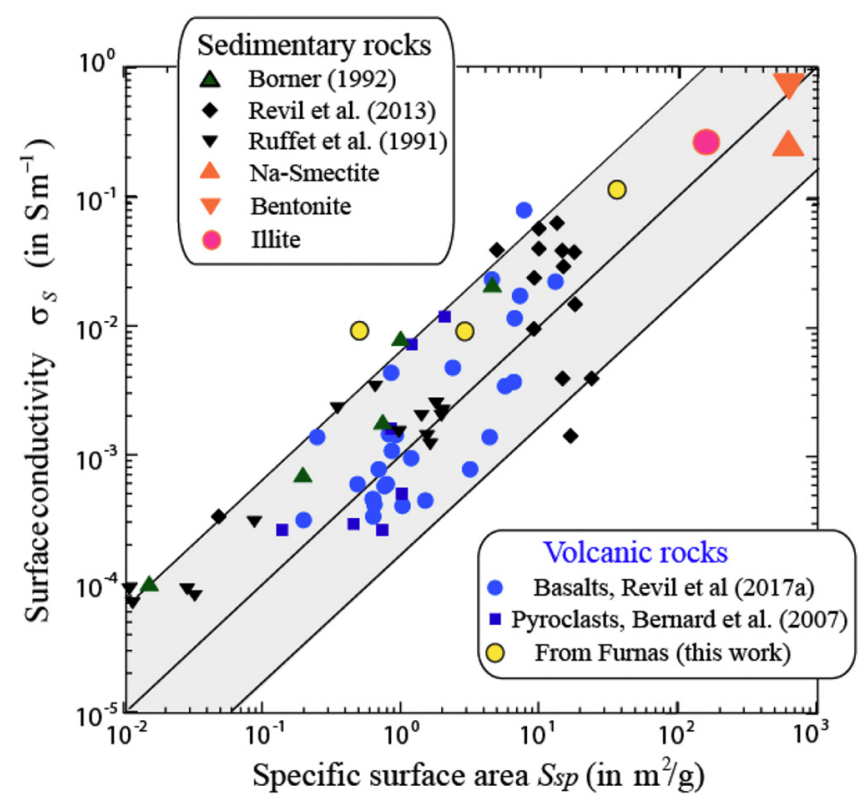

Fig. 3. Relationship between the surface conductivity and the specific surface area taken as a proxy for the alteration of the volcanic rocks (expressed here in $\mathrm{m}^{2} \mathrm{~g}^{-1}$ and measured with the BET method, see Brunauer et al., 1938) for volcanic and sedimentary rocks (no carbonates). Experimental data from Bernard et al. (2007), Börner (1992), Revil et al. (2013), and Ruffet et al. (1991). For the smectite (Na-Montmorillonite), the specific surface area is $700 \mathrm{~m}^{2} \mathrm{~g}^{-1}$ and the surface conductivity was determined from the isoconductivity point (Shainberg and Levy, 1975). The bentonite data are from Lima et al. (2010). The data for illite are coming from Cremers et al. (1966). Note that for Nabentonites the surface area can be as low as $20-40 \mathrm{~m}^{2} \mathrm{~g}^{-1}$ according to Kaufhold et al. (2010).

For this purpose, we developed our own versatile Matlab code to carry out the inversion of electrical conductivity data. Our code is parallelized, flexible in handling different types of input data (e.g., apparent resistivity data or the two components of the electrical field) and can account for various prior information in a broad sense (such as prior geological models), and finally is particularly suitable for handling complex geometries. We first benchmark our code on two synthetic tests. Afterwards, we move on to the inversion of the real field volcanic data. We will also discuss the difficulty in interpreting electrical conductivity tomograms due to the dependence of electrical conductivity on many parameters. This will be shown by discussing the underlying petrophysics of electrical conductivity of volcanic rocks.

\section{Theory and laboratory experiments}

In this section, we first discuss a petrophysical model of the electrical conductivity of volcanic rocks and the approach used to carry out the laboratory measurements. Then, we describe the theoretical background behind our electrical resistivity imaging code in terms of forward and inverse modeling.

\subsection{Electrical conductivity of volcanic rocks: theory}

We first consider volcanic rocks around a magmatic body. The electrical conductivity of such porous volcanic rocks comprises two contributions. The first is the conductivity associated with electrical conduction in the bulk pore space. The second contribution is associated with conduction along the electric double layer coating the surface of the mineral grains. This second contribution is often called surface conductivity. The conductivity of a volcanic rock can be written as (e.g., Revil et al., 2017, 2017)

$\sigma=\frac{s_{w}{ }^{n}}{F} \sigma_{w}+\sigma_{S}$ 


\section{a. Sample holder}

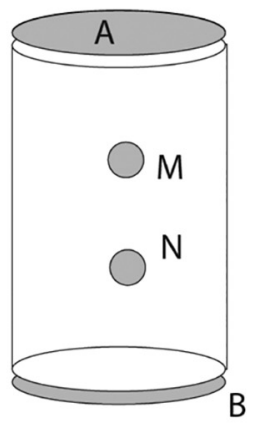

Amplifier unit

\section{b. ZEL-SIP04-V02}

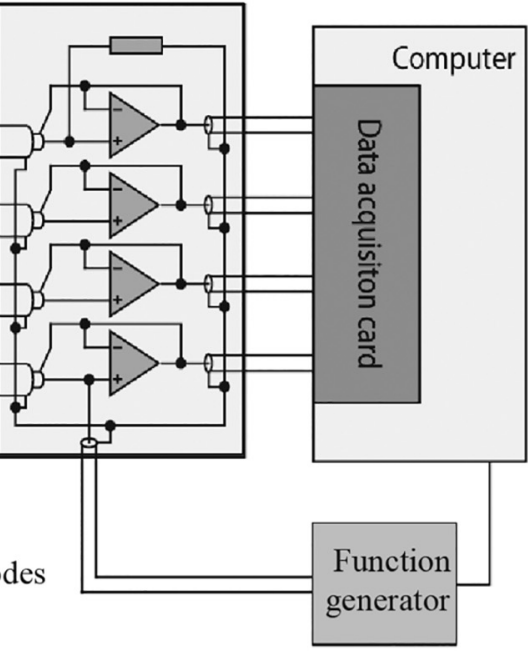

A, B Current electrodes, M, N Potential electrodes

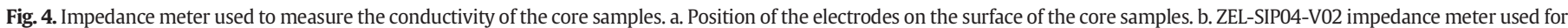

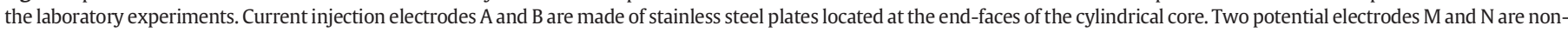

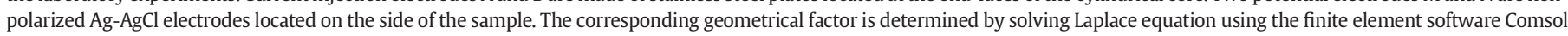

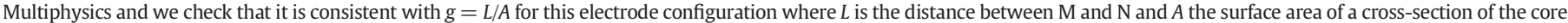
sample.

where $\sigma_{w}$ (in $\mathrm{S} \mathrm{m}^{-1}$ ) denotes the pore water conductivity, $F$ (dimensionless) corresponds to the intrinsic formation factor related to the connected porosity $\phi$ by Archie's law $F=\phi^{-m}$ with $m \geq 1$ (dimensionless) being the porosity exponent (Archie, 1942), $s_{w}$ (dimensionless) denotes the pore water saturation, $n$ (dimensionless) corresponds to the saturation exponent, and $\sigma_{S}\left(\mathrm{~S} \mathrm{~m}^{-1}\right)$ refers to the surface conductivity. For granular materials, $m$ is usually considered to be a grain-shape parameter with a value of 1.5 for spherical grains (Sen et al., 1981) and its value usually increases with alteration (Revil et al., 2017). Fig. 1 shows the general relationship between the formation factor and the porosity of volcanic rocks. This dataset comprises very different types of volcanic rocks and therefore a general power law relationship between the porosity and the formation factor is a correct assumption for volcanic rocks.

Surface conductivity entering in Eq. (1) is related to electrical conduction (i.e., electromigration of the charge carriers) in the electrical double layer coating the surface of the grains. This double layer comprises the Stern layer of sorbed counterions and the diffuse layer. In the model developed by Revil et al. (2017, 2017), the surface conductivity is defined by

$\sigma_{S}=\left(\frac{s_{w}{ }^{n-1}}{F \phi}\right) \rho_{g}\left[\beta_{(+)}(1-f)+\beta_{(+)}^{S} f\right] \mathrm{CEC}$,

where $f$ (dimensionless) denotes the partition coefficient (fraction of counterions in the Stern layer with respect to those contained in both the Stern and diffuse layers, typically $f=0.95$, see Revil et al., 2017, 2017), $\rho_{g}$ is the grain density (in $\mathrm{kg} \mathrm{m}^{-3}$, typically $\rho_{g}=3000 \pm$ $200 \mathrm{~kg} \mathrm{~m}^{-3}$ for volcanic rocks), and CEC is the cation exchange capacity (in $\mathrm{kg}^{-1}, 1$ meq $\mathrm{g}^{-1}=1 \mathrm{~mol} \mathrm{~kg}^{-1}=96,320 \mathrm{C} \mathrm{kg}^{-1}$ ). The CEC denotes the quantity of exchange sites (e.g., aluminol and silanol groups) on the mineral surface that can exchange ions with the pore water at a given $\mathrm{pH}$. The values of the mobility of ions in the diffuse layer is the same as in the bulk pore water (for sodium, we have $\left(\mathrm{Na}^{+}, 25^{\circ} \mathrm{C}\right.$ ) $=5.2 \times$ $10^{-8} \mathrm{~m}^{2} \mathrm{~s}^{-1} \mathrm{~V}^{-1}$ ) and the mobility of the counterions in the Stern layer is smaller (typically $\beta_{(+)}^{S}\left(\mathrm{Na}^{+}, 25^{\circ} \mathrm{C}\right)=1.6 \times 10^{-9} \mathrm{~m}^{2} \mathrm{~s}^{-1} \mathrm{~V}^{-1}$ ). Fig. 2 shows the general trend between the surface conductivity and cation exchange capacity of rocks. At saturation (i.e., $s_{w}=1$ ), we can write $\sigma_{S}=b C E C / F \phi$ with $b=\rho_{g}\left[\beta_{(+)}(1-f)+\beta_{(+)}^{S} f\right]=1.24 \times 10^{-5}$ $\mathrm{kg} \mathrm{m}^{-1} \mathrm{~s}^{-1} \mathrm{~V}^{-1}$ using the values given above for the mass density of the grains and the mobility of the counterions.

The CEC can be generally considered as a rough proxy of the alteration of volcanic rocks (at least for a given alteration path) due to the formation of aluminosilicates (clays and zeolites, see details in Revil et al., 2002). Note that alteration is a very important feature to assess the potential of flank collapse of volcanoes (e.g., Reid et al., 2001). The CEC can be related to the Ishikawa rock alteration index (RAI) used recently to model the alteration of volcanic rocks by circulating hydrothermal fluids using reactive transport numerical models (e.g., Galley et al., 2007; Gibson and Galley, 2007; Goodfellow, 2007). Another proxy of alteration is the specific surface area $S_{S p}$ (in $\mathrm{m}^{2} \mathrm{~kg}^{-1}$ ) of the material. It represents the amount of reactive surface area per unit mass of grains. It can be easily measured using the BET technique (Brunauer et al., 1938). This technique is based on the use of sorption of nitrogen using a powder of the rock. The surface area and the CEC can be related to each other through the surface charge density $Q_{S}$ (charge per unit surface area expressed in $\mathrm{C} \mathrm{m}^{-2}$ ) and we have $Q_{S}=\mathrm{CEC} / S_{S p}$. For clay minerals, the mean charge density $Q_{s}$ is typically 2 elementary charges per $\mathrm{nm}^{2}\left(Q_{S}=0.32 \mathrm{C} \mathrm{m}^{-2}\right)$ and probably does not change with temperature (see Revil et al., 2017, 2017). Fig. 3 shows the general trend between surface conductivity and the specific surface area.

Electrical conductivity depends on temperature. We can use the following linear relationship $\sigma_{w}(T)=\sigma_{w}\left(T_{0}\right)\left(1+\alpha_{w}\left(T-T_{0}\right)\right)$ for the bulk pore water conductivity and $\sigma_{S}(T)=\sigma_{S}\left(T_{0}\right)\left(1+\alpha_{S}\left(T-T_{0}\right)\right)$ for the surface conductivity. In these equations, $T_{0}$ denotes the reference temperature $\left(T_{0}=25{ }^{\circ} \mathrm{C}\right), T$ denotes the temperature of the solution, and $\alpha$ a linear sensitivity coefficient. Therefore, the temperature dependence of the conductivity is then given by $\sigma(T)=\sigma\left(T_{0}\right)\left(1+\alpha\left(T-T_{0}\right)\right)$, and $\alpha_{w} \approx \alpha_{S} \approx 0.02 /{ }^{\circ} \mathrm{C}=\alpha$ (e.g., Vinegar and Waxman, 1984). This temperature dependence is due to the variation of the mobility of the ions with temperature and is valid at last to $200{ }^{\circ} \mathrm{C}$ (see Fig. 6 in Revil et al., 1998). In turn, this temperature dependence is controlled by the temperature dependence of the viscosity of the pore water.

\subsection{Electrical conductivity of volcanic rocks: measurements}

Regarding the electrical conductivity measurements presented in this paper, they are performed with a 4 electrodes technique separating the current electrodes $\mathrm{A}$ and $\mathrm{B}$ from the voltage electrodes $\mathrm{M}$ and $\mathrm{N}$ to 


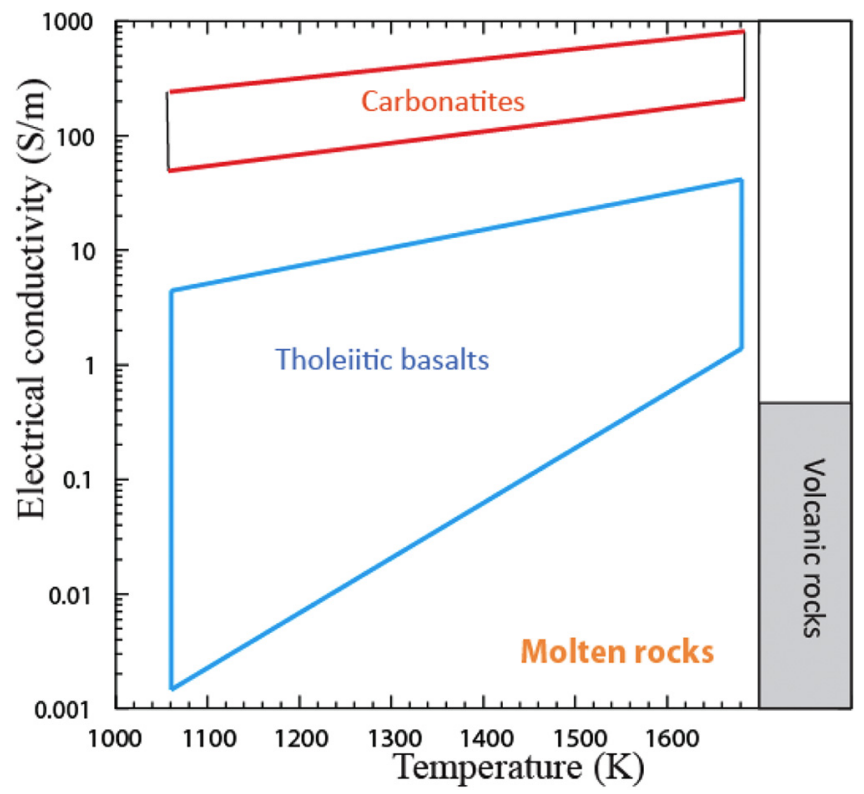

Fig. 5. Typical conductivity for melted carbonatites and tholeiitic basalts (such as in Hawai'ii) according to Gaillard et al. (2008) and Pommier et al. (2008). The carbonatites are usually more conductive than the background rocks. This figure illustrates the difficulty to observe magmatic chambers with molten tholeiitic basalts because of the small contrast of resistivity with the background volcanic rocks (typical range shown on the right side, especially those that are altered close to the conduits). The range of conductivity of the volcanic rocks is determined from the range determined by alteration (CEC, see Fig. 2) and temperature (up to $300{ }^{\circ} \mathrm{C}$ using the temperature dependence discussed in the main text).

avoid the effect of electrode polarization. The instrumentation used for the laboratory measurements is shown in Fig. 4. The cation exchange capacity measurements are performed using the cobalt hexamine technique (Ciesielski et al., 1997) and the specific surface areas using the BET technique (Brunauer et al., 1938). Cobalt is known to have a strong affinity with the surface of the clay minerals. This salt is preferred over the ammonium acetate method because it is sensitive only to the clay minerals and not to the zeolite (Revil et al., 2002; Revil et al., 2017). In our measurements, the cation exchange capacity is determined as the capacity of removing cobalt from a $0.05 \mathrm{~N}$ cobalt(III) hexamine chloride solution, which is characterized by an orange color. The reduction in color during the titration is determined with a calibrated spectrophotometer (Bibby ScientificTM JenwayTM 6320D).

\subsection{The case of molten rocks}

Another component that is probably difficult to resolve through electrical conductivity tomography is the electrical conductivity of the magmatic fluids themselves. Recently, a software called SIGMELTS has been developed by Pommier and Le-Trong (2011) to compute the electrical conductivity of silicate melts and carbonatites as a function of the composition of the melt, the melt fraction, the temperature, the confining pressure, the oxygen fugacity, and the water content (e.g., Tyburczy and Waff, 1983, 1985; Satherley and Smedley, 1985; Gaillard, 2004; Huang et al., 2005; Pommier et al., 2010, 2010; Wang et al., 2006; Yoshino et al., 2008 just to cite few examples). Carbonatites are associated with the melting of carbonate rocks and are therefore specific of very few volcanoes such as in northern Tanzania (Oldoinya Lengai Volcano).

Fig. 5 compares the domain of variations of the electrical conductivity of basalts and carbonatites. Typical variations of the electrical conductivity of shallow magmatic reservoirs are in the range $10^{-3}$ to $1 \mathrm{~S} \mathrm{~m}^{-1}$ depending on the melt fraction (Pommier and Le-Trong, 2011). An important point is therefore that the conductivity of magmatic reservoirs is not necessarily very different from the electrical conductivity of the host volcanic rocks, especially when they are altered. Not accounting for this fact is the source of many misconceptions in the interpretation of magnetotelluric data. Indeed, a number of authors do not account for the conductivity associated with the alteration of volcanic rocks. Another source of high conductivity near magmatic chambers is the formation of hypersaline brines, which are in turn playing a role in the formation of ore deposits (Hedenquist and Lowenstern, 1994).

\subsection{Forward modeling}

We describe now the forward modeling operator for modeling an electrical conductivity survey. Combining Ohm's law with a continuity equation for the electrical charge in an isotropic heterogeneous medium yields the following field equation.

$-\nabla \cdot(\sigma \nabla \psi)=\mathfrak{I}$,

for the electrical potential $\psi$ (in $\mathrm{V}$ ) and where $\sigma\left(\mathrm{S} \mathrm{m}^{-1}\right)$ denotes the electrical conductivity of the material and $\Im$ any volumetric source current term (in $\mathrm{A} \mathrm{m}^{-3}$ ). In electrical conductivity tomography, the source

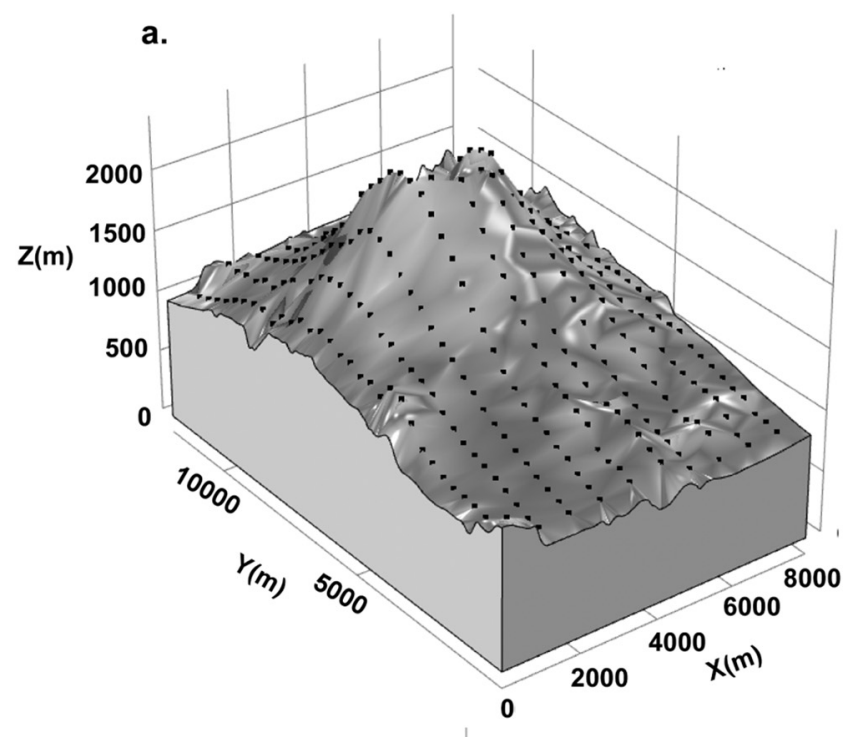

b.

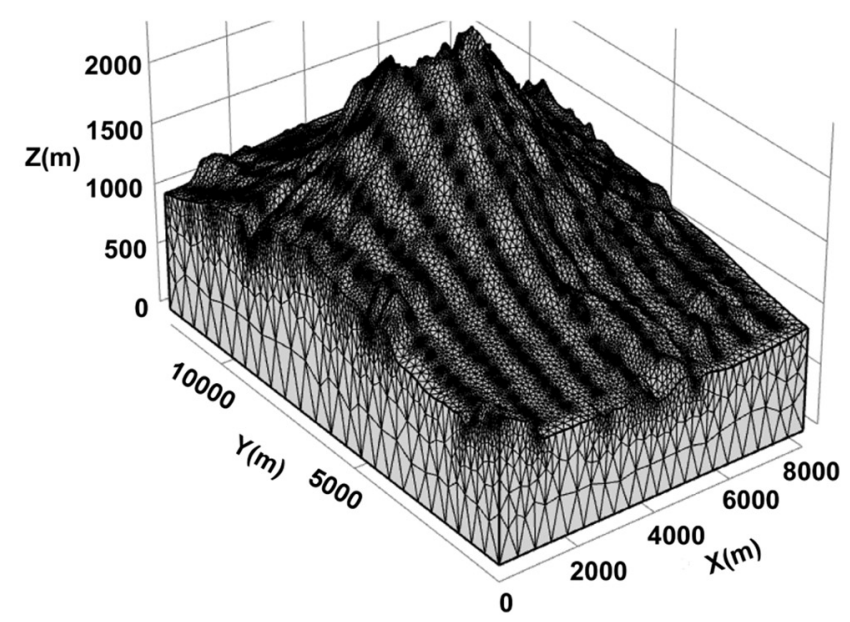

Fig. 6. Synthetic test geometry and mesh. a. Topography and geometry. For the sake of having a realistic test, the topography of this synthetic test is the same as the Mt. St Helens volcano. The black dots denote the locations of the electrodes. b. Finite elements mesh of the simulation domain. The mesh is refined around the electrodes to increase the accuracy of the computations of the forward model. 
current density is generated by multiple current injection/retrieval bipoles perform in the field at localized (punctual) electrodes. Therefore Eq. (3) can be rewritten as

$\nabla \cdot(\sigma \nabla \psi)=-I \delta\left(x-x_{s}\right) \delta\left(y-y_{s}\right) \delta\left(z-z_{s}\right)$,

where $I$ (in A) denotes the intensity of the injected current, $\delta$ is the Dirac (delta) function and $x_{s}, y_{s}$ and $z_{s}$ are the coordinates of the spatial location of the injecting current electrode. Since the current needs to be closed through a circuit connecting a battery to the ground, two current electrodes A and B are used with the same current injected or retrieved at these two electrodes. This is easily handled using Eq. (4) and the superposition principle.

In order to solve Eq. (4), we need to know the physics at the boundary of our domain. Thus we close the problem by setting the following boundary conditions:

$\psi=0$ on $\Gamma_{D}$

$\hat{\mathbf{n}} \cdot \sigma \nabla \psi=0$ on $\Gamma_{N}$

where $\Gamma_{D}$ and $\Gamma_{N}$ denote respectively the boundaries on which the Dirichlet and Neumann conditions are applied and $\hat{\mathbf{n}}$ is a unit outward vector to $\Gamma_{N}$ (used for the ground surface). Eq. (6) simulates the air ground interface for which insulation prevails while Eq. (5) is applied to the ground behavior or in regions far away from the electrodes $\mathrm{A}$ and $B$ (obviously the potential falls to zero at infinity in the conductive half-space).Eq. (4) is referred to as the Poisson equation and it describes the spatial distribution of the equipotentials. If needed, the electrical field can be written as $\mathbf{E}=-\nabla \psi$ (induction neglected). Eq. (6) implies that the normal component of the electrical field vanishes at the ground surface and the electrical field is characterized by two tangential components to this interface. We will come back on this point later.

The Poisson equation is solved with the finite element method through the commercial software Comsol Multiphysics to solve Eq. (4). From a numerical point of view, we consider these successive current injections as independent and then take advantage of parallel computing techniques by performing each injection on a distinct computer core. This will result in dramatic computing performance especially when we are working on a powerful cluster. We adopted this strategy for solving the forward problem by using the Comsol Multiphysics multithread environment on our 32 cores desktop computer. One difficulty in electrical conductivity tomography arises from the fact that, in practice, the target region in which the electrical conductivity measurements are performed is unbounded. Modelers usually encircle the simulation domain with a large buffer domain at the boundary of which they apply a homogenous Dirichlet conditions (Eq. (5) above). A more efficient alternative adopted in the present study consists of padding
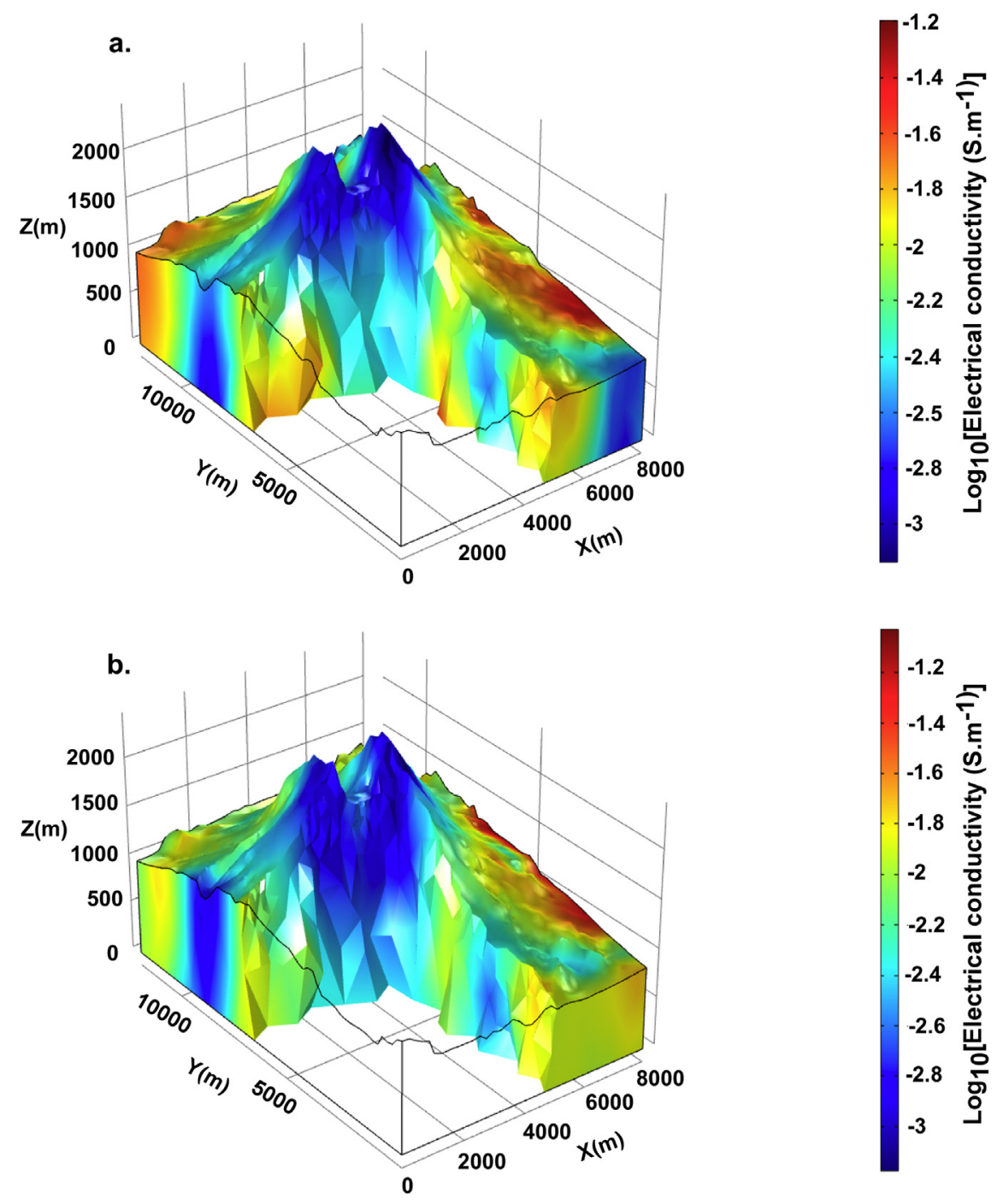

$-1.2$

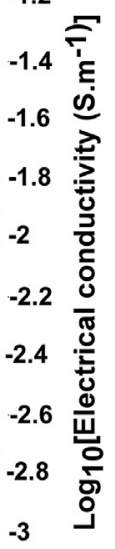

Fig. 7. Synthetic test tomography results using ECT-3D. a. True electrical conductivity field. b. Estimated electrical conductivity field. The major features of the true field are satisfactorily reconstructed. 
Table 1

Relevant information about the case studies simulation parameters. $A$ denotes the number of electrodes or stations (Synthetic 2 ) while $M$ and $N$ denote the number of cells and the number of data, respectively, and finally $I$ denotes the number of iterations at which convergence of the inversion algorithm is reached. Finally, we provide the $R^{2}$-fitting coefficient of the data at the last iteration.

\begin{tabular}{llllll}
\hline Parameter & Synthetic 1 & Synthetic 2 & Yellowstone & Furnas & Kīlauea \\
\hline$A$ & 320 & 49 & 205 & 268 & 465 \\
$N$ & 2160 & 300 & 352 & 1688 & 3859 \\
$M$ & 52,188 & 1000 & 52,984 & 53,111 & 58,918 \\
$I$ & 5 & 4 & 5 & 6 & 6 \\
Data $R^{2}$ & 0.991 & 0.999 & 0.880 & 0.913 & 0.777 \\
\hline
\end{tabular}

the sides and the bottom of the target region with infinite element domains. This will allow taking into account the unboundedness of the target without the need of using computationally expensive large buffer domain.

\subsection{Inverse modeling}

Now that the forward modeling approach has been described, we discuss the inverse modeling step aimed at retrieving the subsurface distribution from measurements performed at the ground surface (possibly in some boreholes). In the software ECT-3D (ECT stands for Electrical Conductivity Tomography), we look in finding a plausible subsurface electrical conductivity model reproducing accurately the observed data (i.e., the apparent resistivity data, or directly the resistances, or the two components of the electrical field). The observed data are collected in a data vector $\mathbf{d}$ of size $N$. This conductivity distribution should reflect the major features of the subsurface with an issue related to the fact that the resolution of a survey decreases quickly with the distance from the electrodes. Mathematically, this is an inverse problem whose solution is a model parameter vector $\mathbf{m}$ of size $M$ that contains the logarithm of the conductivity values for each cell describing the subsurface (discretization).

In practice, we discretize the region of interest into a grid. Then, we assign the logarithm of the electrical conductivity value to each cell of the grid. These values are referred to as being the unknowns and, given the data, we try to find the optimal model. When working on field areas with complex surface topography such as volcanoes, the use of unstructured grids like tetrahedral ones is favored. In fact, unstructured grids offer higher freedom in approximating the complex

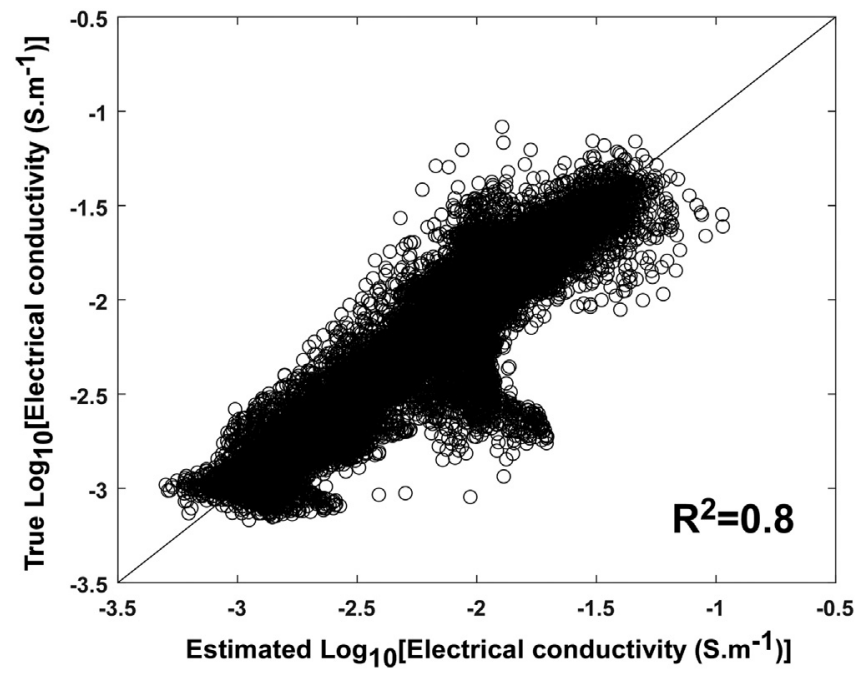

Fig. 8. Scatterplot of the true conductivity versus the estimated one for the synthetic example. The scatterplot follows a general linear trend (1:1) showing that the inversion was successful in terms of retrieving the true conductivity structure of the volcano. There are however few areas of low sensitivity that are not well-recovered.

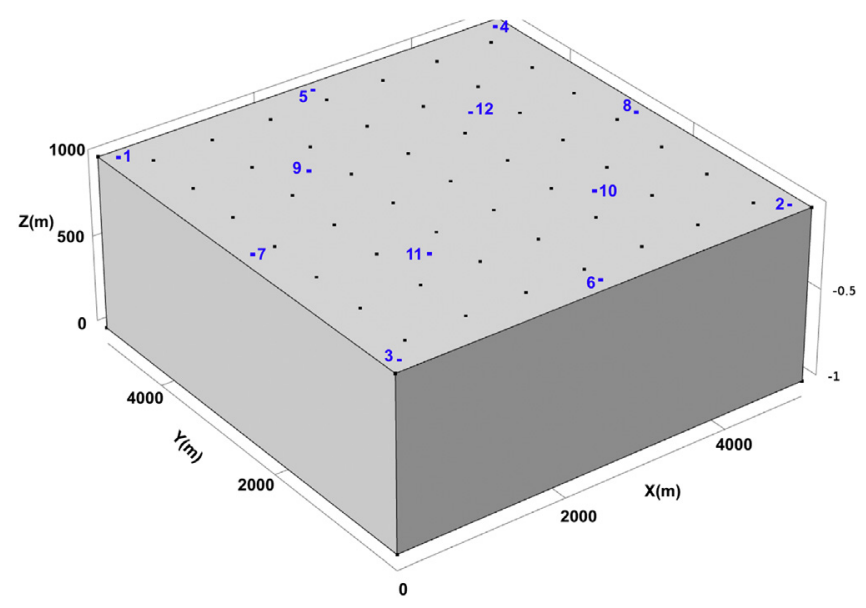

Fig. 9. Geometry of the second synthetic case simulating an acquisition with the FullWaver instrument. Each black dot represents a station for which the two components of the electrical field are recorded in the $x$ - and $y$-directions. We simulate 49 receivers. We simulated 6 current injections by switching the positions of the current electrodes A and $B$ (blue numbered dots). The current injection are performed on the bipoles $[A, B]=[1$ 2], [3 4], [5 6], [7 8], [9 10], [1112].

geometry and their effect on the subsurface potentials. However, we still need a high number of cells to accurately reproduce the features of the geometry, typically these unknowns outnumber the number of measurements $N$ (i.e., $M \gg N$ ), making the inverse problem usually strongly undetermined. In addition, this inverse problem is non-unique as it has an infinite number of solutions.

We discretize the simulation domain into $N$ tetrahedrons. Following the concepts introduced by Tikhonov and Arsenin (1977), we define the following objective function using the following form (e.g., Hansen and
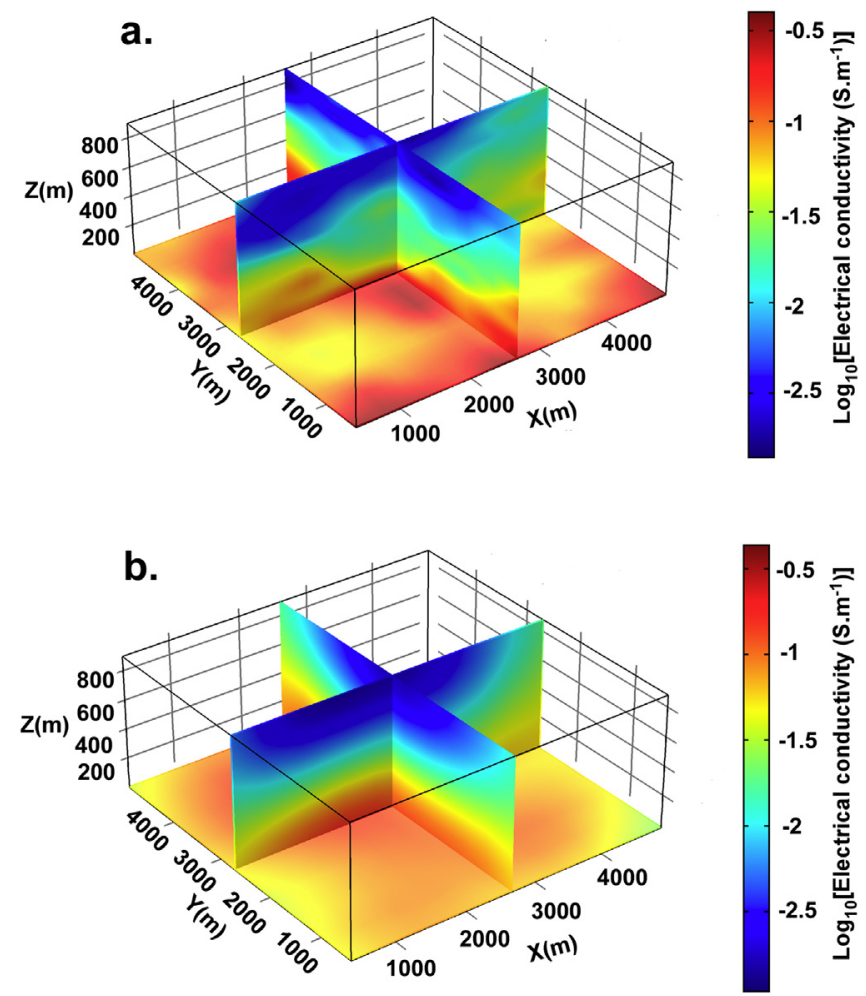

Fig. 10. Second synthetic case used to benchmark ECT-3D. a. True electrical conductivity field. b. Inverted electrical conductivity field using the two components of the electrical field (300 measurements). With 6 current injections only, we can already get a fair reconstruction of the electrical conductivity field. 


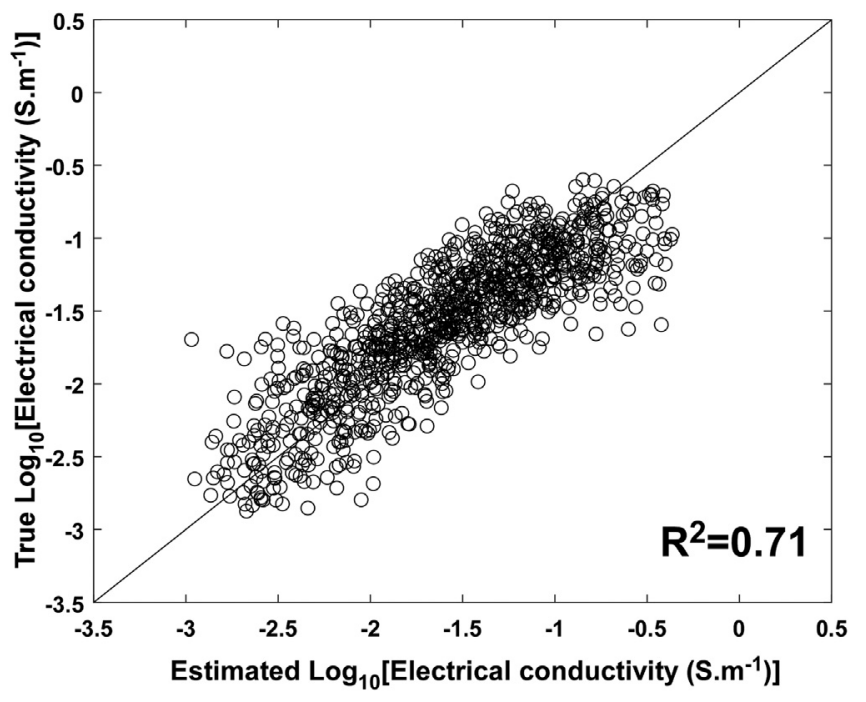

Fig. 11. Scatter plot of true conductivity field versus the estimated one for the second synthetic case study. We note that despite the small number of injections, the conductivity field is well-reconstructed.
O'Leary, 1993; Hansen, 1998):

$L(\mathbf{m})=\left\|\mathbf{W}_{\mathbf{d}}(\mathbf{d}-F(\mathbf{m}))\right\|_{2}^{2}+\lambda\left\|\mathbf{W}_{\mathbf{m}}\left(\mathbf{m}-\mathbf{m}_{\text {ref }}\right)\right\|_{2}^{2}$,

where the subscript 2 refers to the L2-norm, $\mathbf{m}=\left[\log _{10}\left(\sigma_{1}\right), \log _{10}\right.$ $\left.\left(\sigma_{2}\right), \ldots, \log _{10}\left(\sigma_{M}\right)\right]^{T}$ denotes the vector model (logarithms of the electrical conductivity of each cell), $N$ corresponds therefore to the number of unknowns. The use of logarithms ensures the positiveness of the electrical conductivities in each cell (in other words, the recovered electrical conductivity model contains necessarily, by construction, positive values). To each tetrahedron, we assign an electrical conductivity $\sigma_{j}$. The vector $\mathbf{d}=\left(\log _{10} R_{1}, \log _{10} R_{2}, \ldots, \log _{10} R_{N}\right)$ is the data vector where $R_{i}$ refers to the resistances or the two components of the electrical field at the receiver $i$. Applying decimal logarithm to the data vector shrinks the range of variability of the data and therefore contributes to stabilize the inverse process by not overweighting the large values of resistances. In Eq. (7), $\mathbf{W}_{\mathbf{d}}$ is taken as a diagonal matrix. Its diagonal components are equal to the inverse of the standard deviation of the noise contaminating the recorded data. In Eq. (7), F(.) denotes the forward modeling operator solving numerically the Poisson equation using the finite element approach. The objective function $L(\mathbf{m})$ is composed of two terms, the first one is related to the data misfit and the second one deals with the constraints that we impose on the model to be smooth to cope with the non-uniqueness of the inverse problem. We need a compromise between these two terms to obtain a physically

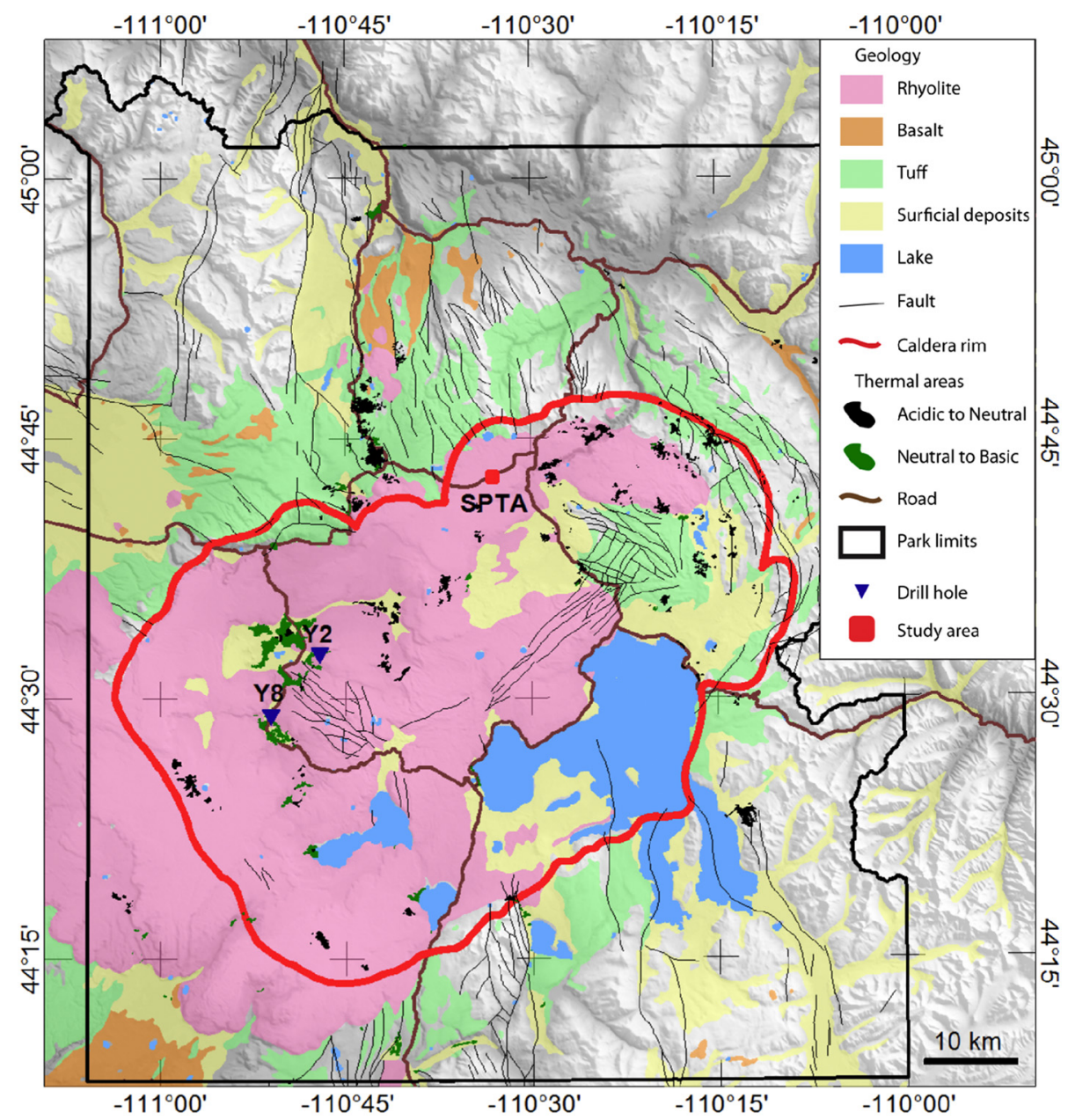

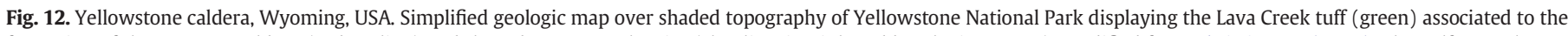

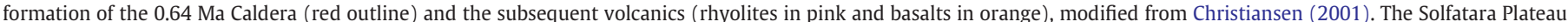

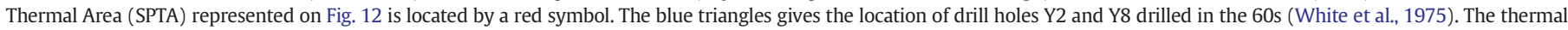

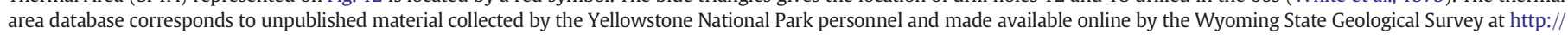
www.wsgs.wyo.gov/gis-files/geothermal.zip. 


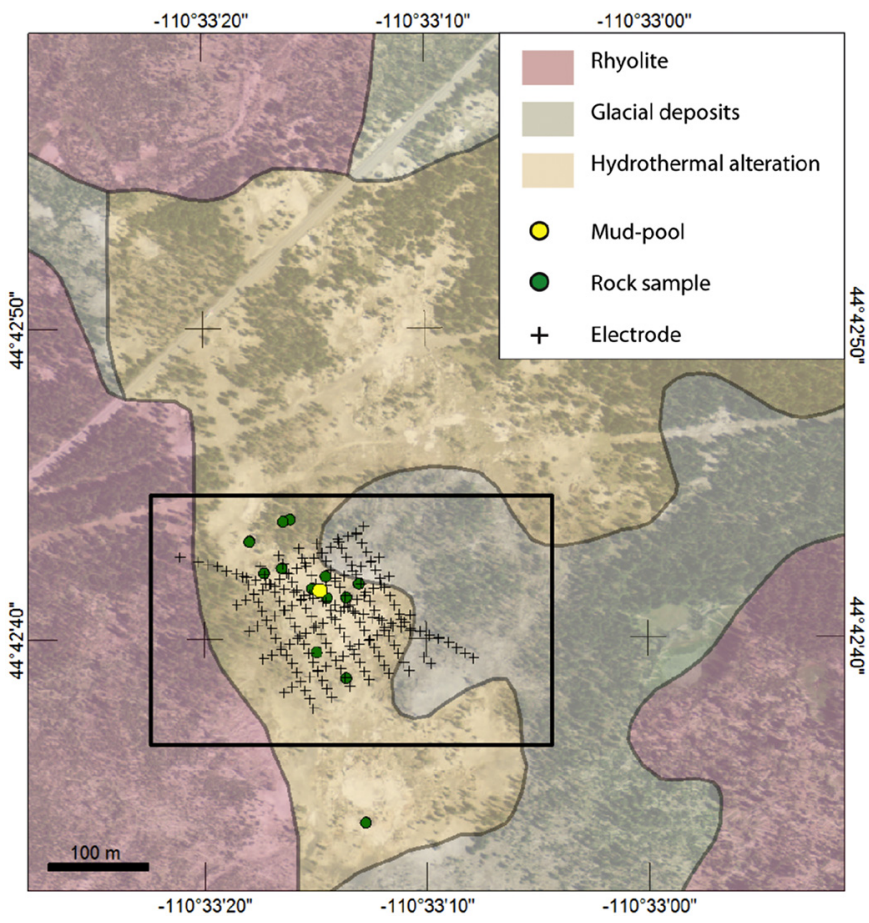

Fig. 13. Geological map of the Solfatara Plateau vapor-dominated thermal area along the northern boundary of the Yellowstone caldera (modified from Christiansen, 2001) showing the location of electrodes (black crosses) and rock samples collected in the field (green circle). During the course of the survey, the area displayed a small mudpool (yellow circle). The black outline display the location of the area displayed on Figs. 14 and 15. The survey comprises 205 electrodes and 352 resistance data. The yellow circle corresponds to the mud pool.

plausible and meaningful model that reduces the data misfit. This crucial task is achieved by the regularization parameter $\lambda$ that serves as a balance between these two terms. Finally, $\mathbf{W}_{\mathbf{m}}$ denotes a roughening matrix and minimization of the associated regularization term is done in order to enhance smoothing of the tomogram during the inversion.

If we work on structured grids, computing the roughening operator $\mathbf{W}_{\mathbf{m}}$ is straightforward because it can be obtained by evaluating the first-order or second-order derivatives on the grid. For unstructured grids, things are more complicated as we have to pay attention to the connections between the neighboring tetrahedrons (e.g., Günther et al., 2006; Key, 2016; Schwarzbach and Haber, 2013). We consider that two cells of the grid are neighbors if they share a common face. We define the roughening matrix $\mathbf{W}_{\mathbf{m}}$ as

$\mathbf{W}_{\mathbf{m}}=\left\{\begin{array}{c}\mathbf{W}_{\mathbf{m}_{T, i}}=1 \\ \mathbf{W}_{\mathbf{m}_{T, j}}=-1\end{array}\right.$

where $T$ is the common triangle shared by two cells $i$ and $j$. In practice, the matrix $\mathbf{W}_{\mathbf{m}}$ is usually large and sparse and it has $2 f$-non zero elements, where $f$ denotes the number of triangular faces of the unstructured grid.

By minimizing Eq. (7), we find the best conductivity model honoring the observed data. The minimization of Eq. (7) is performed using a Gauss-Newton approach. Several techniques exist to choose the optimal value of the regularization parameter $\lambda$. For instance, the L-curve approach (e.g., Hansen, 1998) and the generalized cross-validation technique (e.g., Wahba and Wang, 1995). All of these methods proved to be successful in many cases but their usage can be questionable, as sometimes they may not lead to the proper convergence of the inverse problem to a meaningful solution. In the present paper, we use a straightforward and classical technique in which we start the inversion with a large value of $\lambda$ and we keep dividing $\lambda$ by 2 at each iteration step until the convergence is reached (e.g., De Groot-Hedlin and Constable, 1990; Morozov and Stessin, 1993).

Various convergence criteria can be used such as those associated with the convergence of the data misfit (the variation between two successive iterations can be smaller than a specified small number $\varepsilon$ ). The minimization of the objective function $L(\mathbf{m})$ with the Gauss-Newton method, leads to the following model update at iteration $i$

$\mathbf{m}_{i+1}=\mathbf{m}_{i}+\Delta \mathbf{m}_{i}$

where $\Delta \mathbf{m}_{i}$ denotes the model perturbation vector. This vector is the solution of the linearized problem and given through the following projection

$$
\begin{aligned}
& \left(\mathbf{J}^{T} \mathbf{W}_{\mathbf{d}}^{T} \mathbf{W}_{\mathbf{d}} \mathbf{J}+\lambda \mathbf{W}_{\mathbf{m}}^{T} \mathbf{W}_{\mathbf{m}}\right) \Delta \mathbf{m}_{\mathbf{i}} \\
& \quad=\mathbf{J}^{T} \mathbf{W}_{\mathbf{d}}^{T} \mathbf{W}_{\mathbf{d}}\left(\mathbf{d}-F\left(\mathbf{m}_{\mathbf{i}}\right)\right)-\lambda \mathbf{W}_{\mathbf{m}}^{T} \mathbf{W}_{\mathbf{m}}\left(\mathbf{m}_{\mathbf{i}}-\mathbf{m}_{\mathbf{r e f}}\right)
\end{aligned}
$$

where $\mathbf{J}$ denotes the Jacobian matrix given by

$\mathbf{J}_{i j}=\frac{\partial \log _{10} \mathbf{R}_{i}}{\partial \log _{10} \boldsymbol{\sigma}_{j}}$

The most time consuming part of the inverse process is the assembly of the Jacobian matrix and this needs to be done at each iteration with the Gauss-Newton algorithm. To alleviate the high computational cost related to this assembly, we only determine the Jacobian matrix at the first iteration on a homogenous electrical conductivity model using the adjoint operator method, and then we use a Broyden update approach (see Broyden, 1965; Nocedal and Wright, 2006) to update the Jacobian matrix at the following iterations without the need of computing

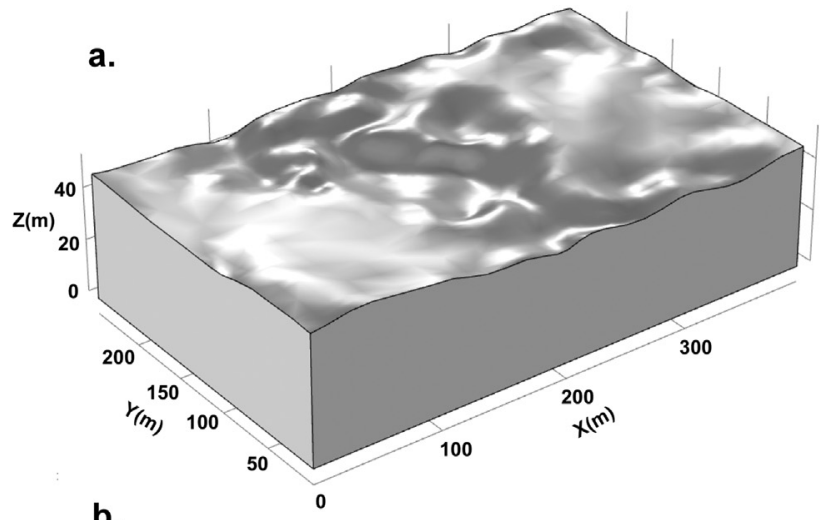

b.

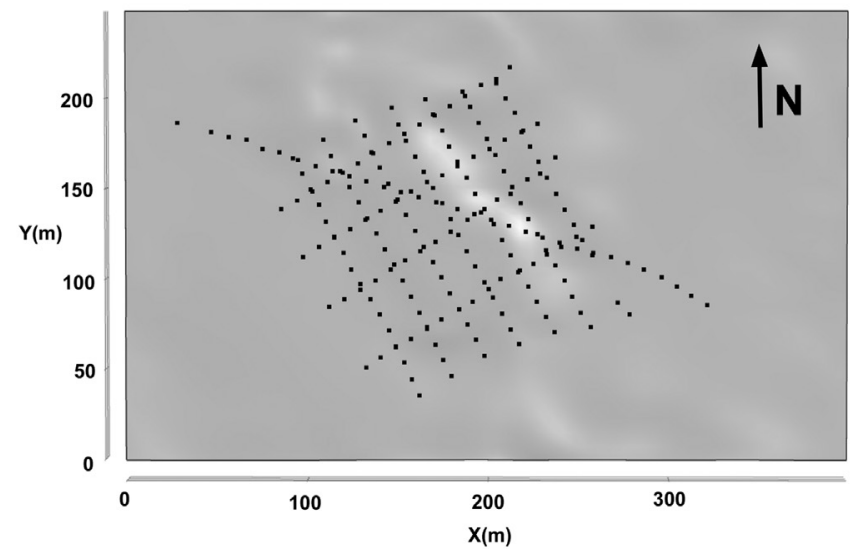

Fig. 14. Geometry of the case study at the Solfatara Plateau vapor-dominated thermal area along the northern boundary of the Yellowstone caldera. a. 3D representation of the simulation domain. b. Location of the electrodes. We used a 3D rendering of the observed topography with the force gradient superimposed grey shades. 
it completely. As a side note, the matrix $\mathbf{J}$ is large and dense but when we examine its structure, we can notice that it contains several entries that are very small because as we get far from the current sources, the sensitivity decreases quickly. Therefore those entries will not bring much information and can be replaced by zero to save $\mathbf{J}$ as a sparse matrix.

When we deal with large-scale inverse problems, the matrices involved can be ill-conditioned and it is more efficient to use conjugate gradient type methods to solve the associated linear systems. Conversely to the conventional conjugate gradients method, the biconjugate gradient method does not require the matrix of the linear system to be symmetric and positive definite. We use the biconjugate gradient the method to solve our problem.

\section{Synthetic tests}

In this section, we benchmark the code ECT-3D discussed in the previous section on two distinct synthetic tests. The first one is a synthetic test with a strong topography. The second synthetic test corresponds to a large scale survey using the type of approach associated with the use of the FullWaver from IRIS. In this case, each independent station records the two components of the electrical field during the injection of electrical current.

\subsection{Modeling the effect of strong topographies}

A synthetic case is used to benchmark our 3D inversion algorithm. Our goal is to show that our code is capable of handling severe topographical effects and provides reliable electrical resistivity characterization of the subsurface. The geometry of this synthetic model has been constructed from a digital elevation model (DEM) of Mt. St. Helens volcano (this DEM file has a resolution of $1 \mathrm{~m}$ and is freely downloadable from https://nationalmap.gov/elevation.html). We ran our simulations on the domain that is represented in Fig. 6a. It covers an area of $12000 \mathrm{~m} \times 8000 \mathrm{~m}$ and reaches a maximum height of $2433 \mathrm{~m}$. As stated in Section 2 above, the simulation domain is padded with infinite element domains from all the sides except the upper one that represents the ground surface in contact with the air. This is done to reduce the effects of the boundary conditions on the simulations in the domain of interest. We use linear shape functions for the finite elements discretization that is used to solve the forward problem. The tetrahedral mesh used for running the forward problem is represented Fig. 6b. This mesh is refined in the vicinity of the electrodes to increase the accuracy of the numerical solution. The true conductivity model is represented in Fig. 7a and was generated with an exponential variogram using the geostatistical software SGEMS (Deutsch and Journel, 1992). We first generate this field on a rectangular of 48,000 cells. For this purpose we
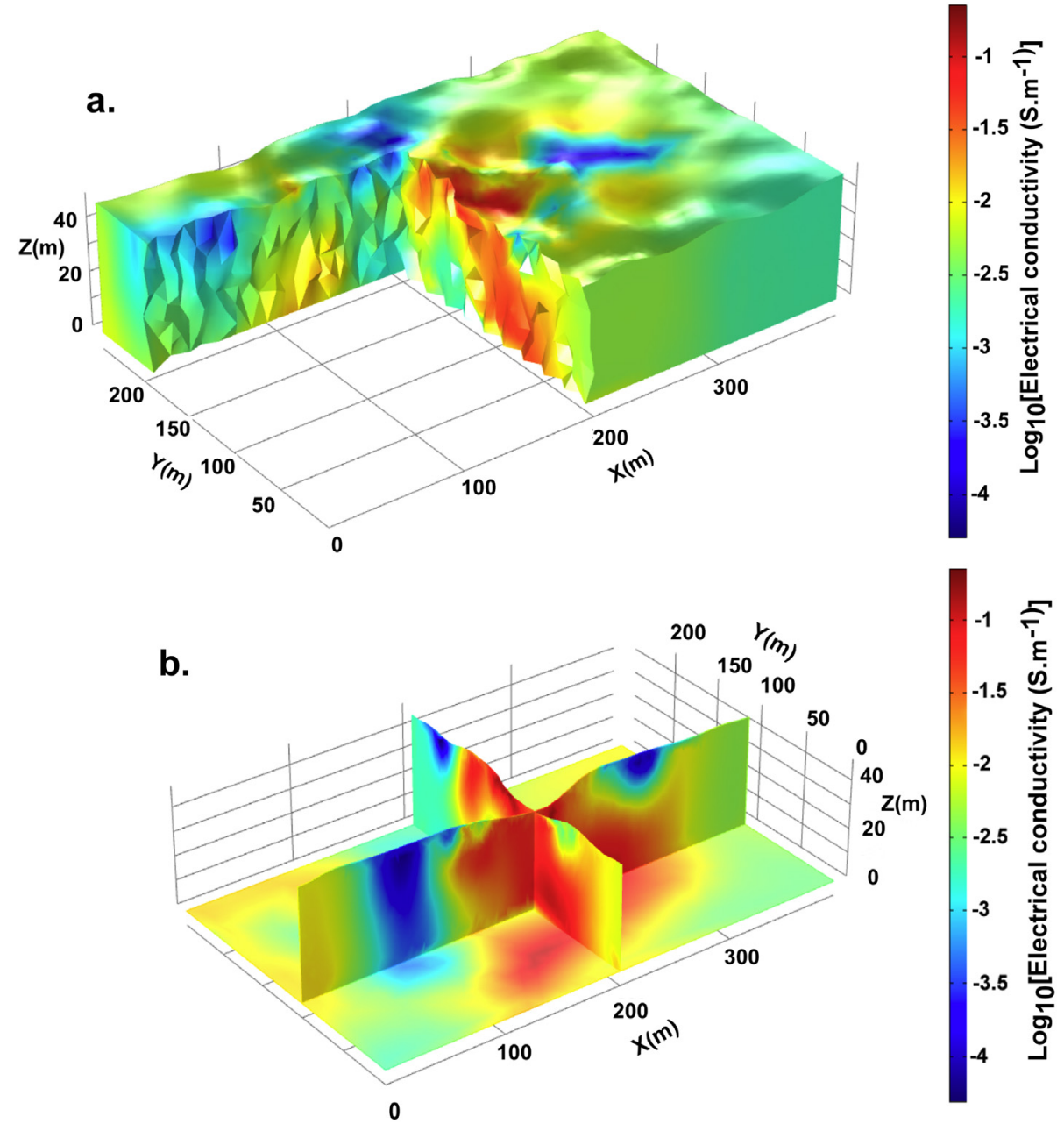

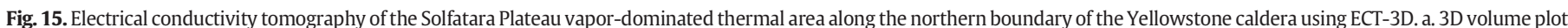

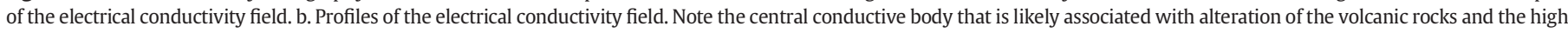

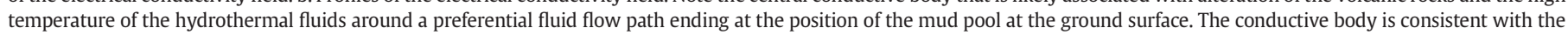
position of the mud pool at the ground surface shown in Fig. 13. 


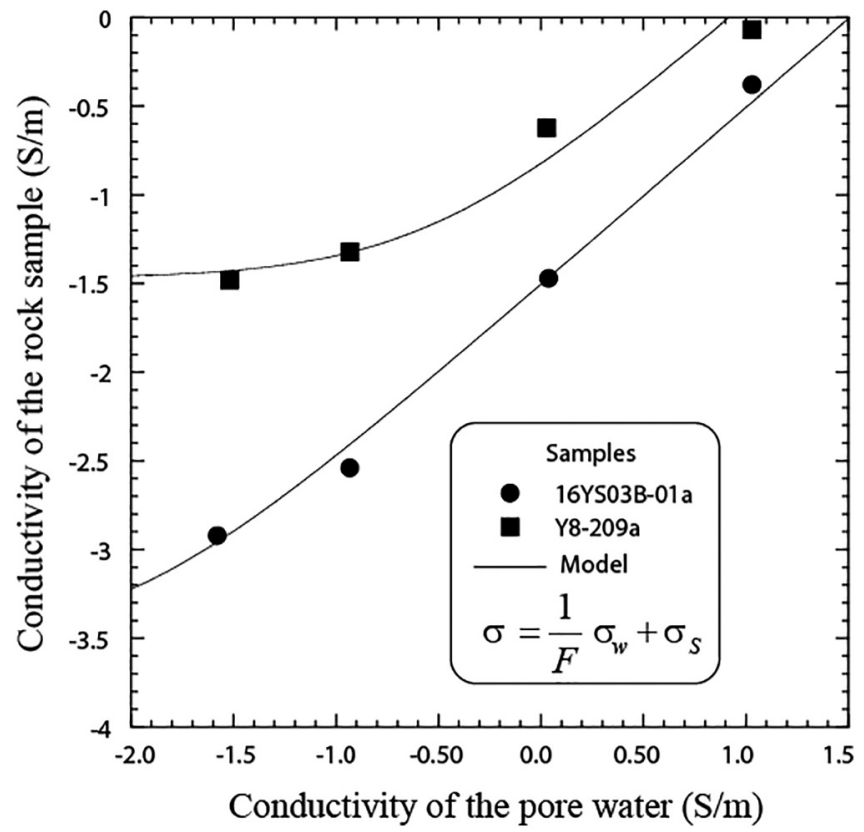

Fig. 16. Conductivity of two volcanic rocks versus the conductivity of the brine ( $\mathrm{NaCl}, 25$ $\left.{ }^{\circ} \mathrm{C}\right)$ for some samples from Yellowstone. Samples 16YS03B-01a $\left(F=32.1, \sigma_{S}=\right.$ $\left.0.00029 \mathrm{~S}^{-1}\right)$ is characterized by a low surface conductivity while sample Y8-209a ( $F=$ $8.57, \sigma_{S}=0.034 \mathrm{~S}^{-1}$ ) is characterized by a much higher surface conductivity and is highly altered. Measurements reported at $10 \mathrm{~Hz}$

used the following Gaussian variogram: $\gamma(h)=2\left\{1-\exp \left[-(h / 50)^{2}\right]\right\}$. The dimension of each cell of this gird is $307.69 \mathrm{~m} \times 275.86 \mathrm{~m} \times 64.1 \mathrm{~m}$. Then this conductivity field is interpolated from the rectangular grid to the unstructured mesh using a nearest neighbor interpolation so that we obtain the true conductivity field illustrated in Fig. 7a. This conductivity distribution assigns a resistive structure to the summit of the volcano and becomes more conductive downward to mimic a geothermal system. In addition, a conductive area is present around the edifice of the volcano. We recall that this conductivity model is purely hypothetical and does not reflect the true structures of Mt. St. Helens volcano. We believe that this example constitutes a realistic simulation scenario for benchmarking our inversion procedure. Our goal is to assess to which extend we are able to delineate and image the different structures of the volcano. We use 10 profiles composed of 32 electrodes each. A distance of $800 \mathrm{~m}$ separates the profiles and the spacing between the electrodes is $355 \mathrm{~m}$. This results in an electrode network covering the entire area of interest. We use a dipole-dipole configuration, providing 470 current injections and $N=2160$ resistance measurements. All the measured resistances have been artificially contaminated with a $2 \%$ Gaussian noise to mimic the noise sources that may corrupt the data under real field conditions. The inversion grid consists of $M$ $=52,188$ tetrahedrons and the conductivity of each tetrahedron is estimated. These tetrahedral cells have different sizes: near the surface the maximum length of these cells is $18 \mathrm{~m}$ and, at the bottom of the domain, larger cells with a maximum length of $336 \mathrm{~m}$ are used.

The use of tetrahedral cells is motivated by the high versatility they offer for representing complex geometrical shapes like those encountered when dealing with the extreme topographical effects of volcanic areas. We assume that the true conductivity distribution is unknown (no prior information available) and we use the inverse scheme described in Section 2 to recover its spatial distributions while fitting the observed resistances. The inversion process is launched with an initial model given by the geometric mean of the apparent resistivities. Fig. $7 \mathrm{~b}$ shows the estimated 3D conductivity field. The algorithm has converged at iteration 5 (see Table 1 ).

The major features are very well-recovered in terms of shape, magnitude and locations. We notice that some structures at the corners appear to be smoother than true ones. This is due to the weak sensitivity caused by the lack of measurements in these areas. Indeed to be able to image a target, we need to make sure that the current goes through it, which is not the case for the corners regions. Plotting the true versus the estimated conductivity shows a linear trend (see Fig. 8). This confirms the results obtained by visual inspection of the reconstructed and true fields. The data correlation coefficient $R^{2}$ is 0.991 which means that the resistance data were reproduced with a high fidelity and the data RMS is $0.108 \mathrm{Ohm}$. Although being hypothetical, this example was designed to mimic the real field conditions and the results

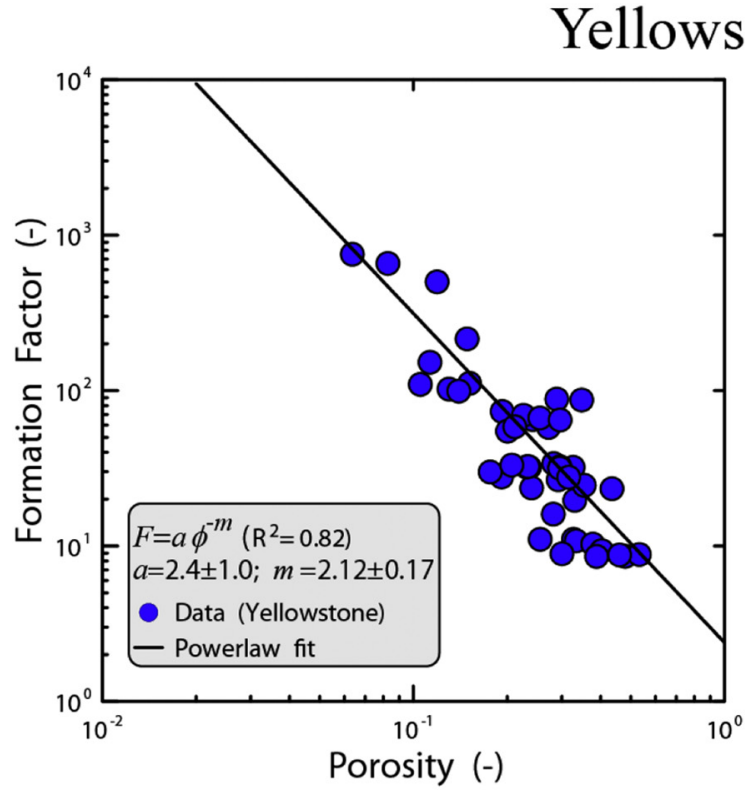

tone dataset

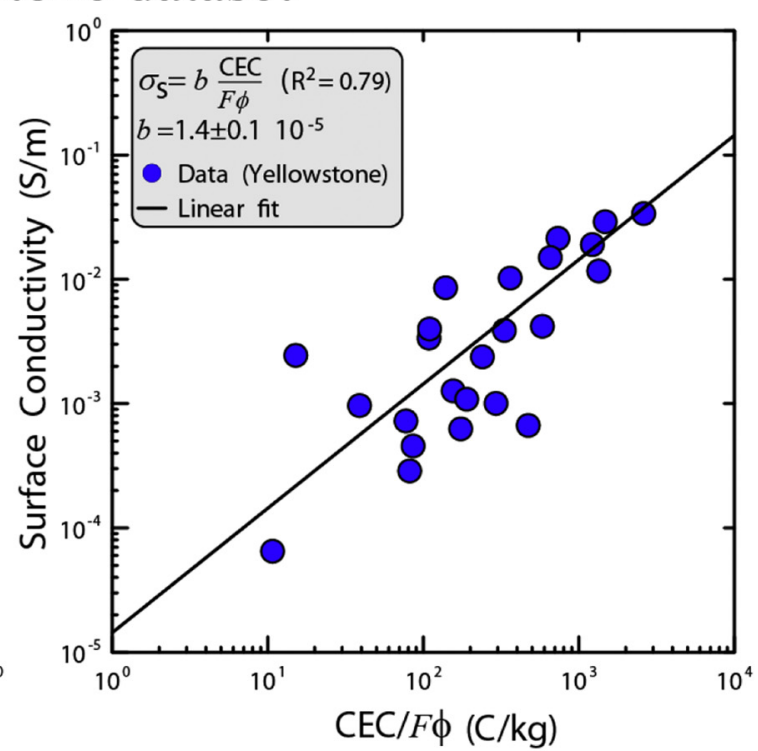

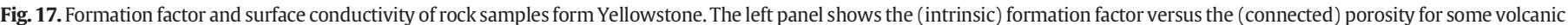

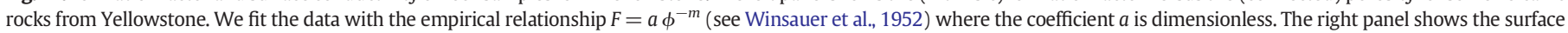

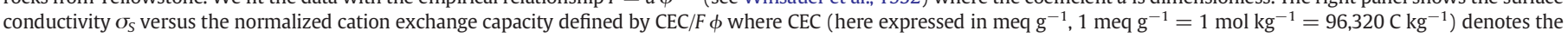
intrinsic cation exchange capacity, $F$ the formation factor, and $\phi$ the connected porosity. Measurements reported at $10 \mathrm{~Hz}$. 


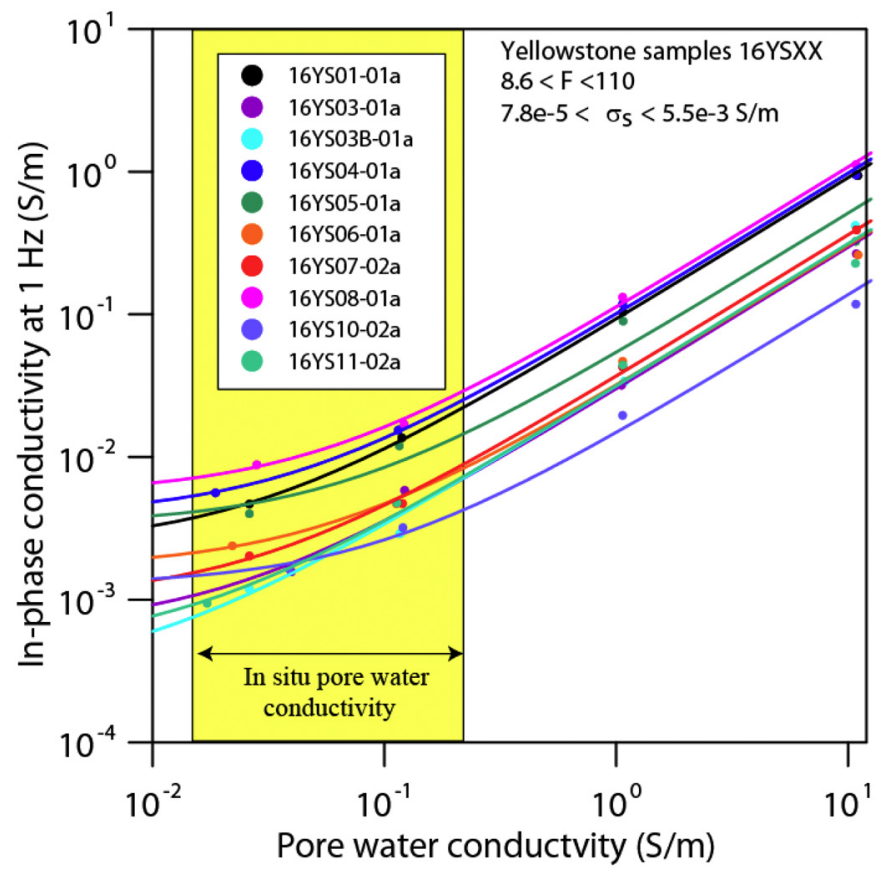

Fig. 18. Conductivity versus the pore water conductivity for the core samples from the Solfatara Plateau vapor-dominated thermal area along the northern boundary of the Yellowstone caldera. We have also shown (in yellow) the range of pore water conductivity (at $25^{\circ} \mathrm{C}$ ) for this type of sulfate-rich hydrothermal waters at low pH values.

of our inversion tool are satisfactory. The topography of such volcanic cones is a clear advantage in improving the resolution of conductivity tomogram. Indeed, it allows the use of current electrodes on both parts of the volcano, focusing the current in the structure and increase the sensitivity of the measurements.

\subsection{Measuring the two components of the electrical field}

The recently developed FullWaver instrument from IRIS opens new possibilities in order to perform large scale electrical conductivity tomographies over volcanic edifices and geothermal systems. It can be used with transmitters of different powers, making its depth of investigation ranging from few meters to few kilometers. We believe that such distributed systems as the Fullwaver represent the future of the electrical conductivity measurements technology for volcanoes. We perform here a synthetic test in which we simulate a large scale acquisition with this type of system. The aim of this synthetic test is therefore to simulate an electrical conductivity survey that is acquired, using such an instrumentation, and to check what results could be achieved with only a small number of current injection.

We consider a synthetic 3D domain covering a volume of $5 \mathrm{~km} \times$ $5 \mathrm{~km} \times 1 \mathrm{~km}$. On the ground surface, we consider that the acquisition is performed by a set of 49 stations, separated from each other by $700 \mathrm{~m}$ (Fig. 9). In practice, we use two current electrodes A and B whose positions can be switched during the acquisition. For each current bipole ( $A$, $\mathrm{B})$, the two components of the electrical field $E_{x}$ and $E_{y}$ are recorded on all the stations, resulting quickly in a high amount of data (the normal component of the electrical field to the ground surface is zero because of the insulating boundary condition at this interface). For our synthetic test, we used the true electrical conductivity distribution shown in Fig. 10a. As we are working on a flat ground surface, we did not use unstructured grids for our inverse modeling. We instead discretized the simulation domain into a $10 \times 10 \times 10$ cubic cells (10 cells in each direction). This gives 1000 unknowns and we perform 6 current injections only. The distance between the current electrodes is $6646 \mathrm{~m}$ for bipoles $(1,2)$ and $(3,4), 4700 \mathrm{~m}$ for bipoles $(5,6)$ and $(7,8), 2828.5 \mathrm{~m}$ for bipoles $(9,10)$ and $(11,12)$. The forward problem is solved on an unstructured

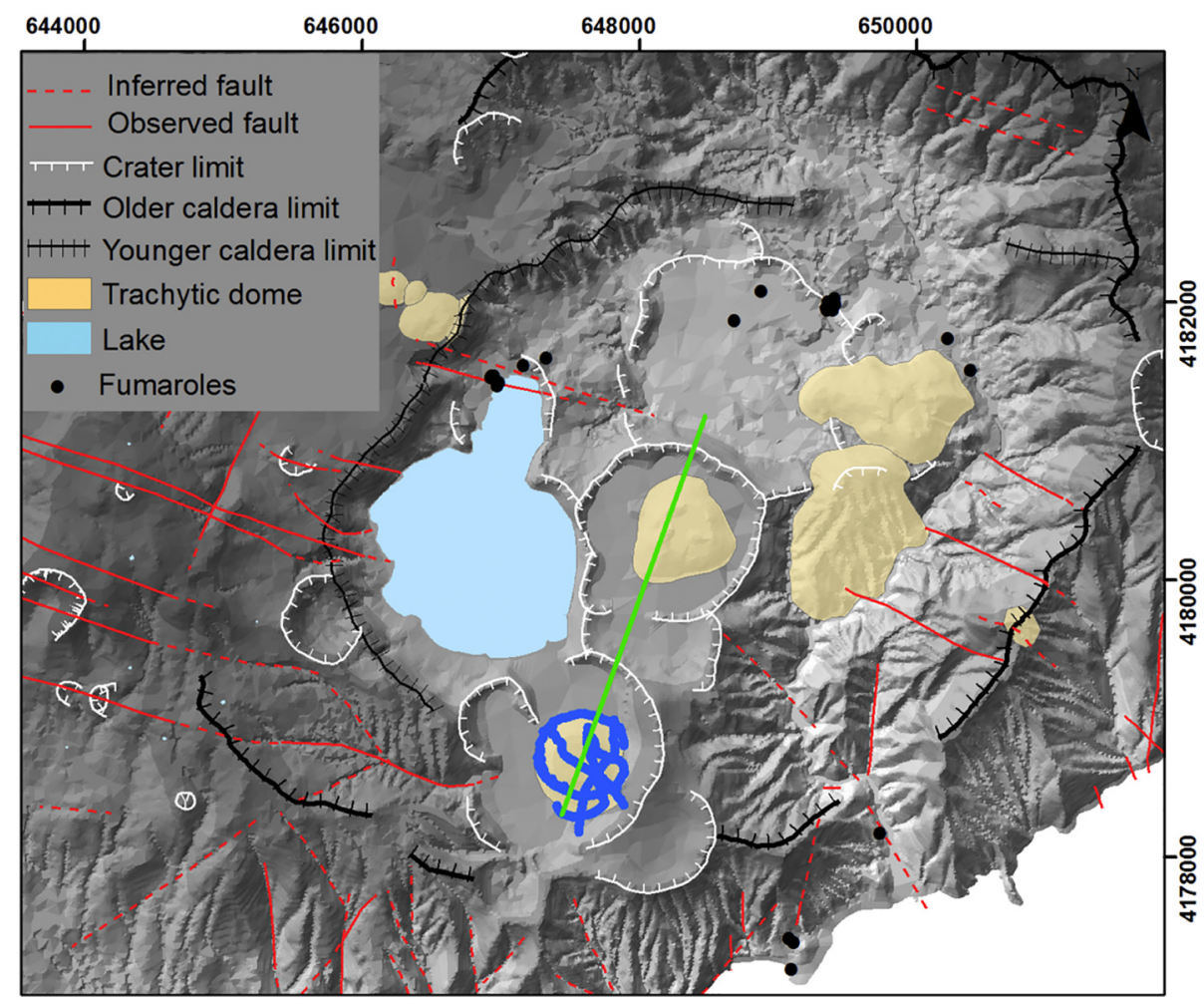

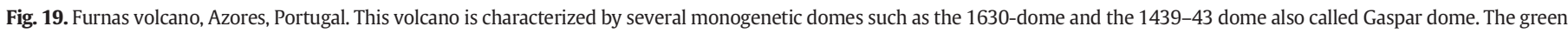
line denotes the position of the magnetotelluric (MT) profile shown in Fig. 21 and the blue dots denote the position of the electrodes used for the electrical resistivity tomography. 
tetrahedral mesh. We recall that here, the measurements are the electrical field components and not the apparent resistivities as for classical electrical conductivity surveys. The total number of measurements acquired for the synthetic tests is 300 . A $5 \%$ white Gaussian noise was added to the simulated data. Modeling parameters are summarized in Table 1.

We launch the inversion process with an initial conductivity model that represents the geometric mean of the true conductivity model. We are interested in seeing if, despite the small number of performed current injections, we are able to reconstruct the main subsurface structures. The convergence criterion was to stop the inversion when the absolute value of the difference between the objective functions values of two successive iterations is smaller than 0.001 . Such condition was met after 5 iterations, resulting in the 3D tomogram shown in Fig. 10b. The algorithm has converged at iteration 4 (see Table 1).

The major anomalies of the true conductivity field are well recovered by the tomogram. The upper domain is well-retrieved with the correct range of conductivity $\left(10^{-3} \mathrm{~S} . \mathrm{m}^{-1}\right.$ and $\left.10^{-2.5} \mathrm{~S} . \mathrm{m}^{-1}\right)$. The lower part of the investigated domain appears smoother than the true distribution because of a loss of sensitivity related to our electrodes configuration and also the limited number of current injections (comparing Fig. 10a and Fig. 10b). The scatterplot of the true conductivities versus the estimated ones clearly shows a linear 1:1 trend showing generally a good reconstruction in the domain (Fig. 11). Therefore, in field conditions, even with a small number of current injections, we can reconstruct the major structures of the subsurface.

\section{Applications}

In this section, we show how electrical conductivity tomography can be an asset in characterizing the 3D structures of volcanoes and identifying their hydrothermal systems. We demonstrate the robustness of the code that we developed by applying it to three different case studies that have been chosen because of their complementarity: (i) The first test site corresponds to a vapor dominated area in Yellowstone National Park. Our initial goal was to provide a high-resolution 3D electrical conductivity image of the subsurface. Such tomography was a first step to obtain new insights on the processes controlling the transport of heat and mass in Yellowstone's dynamic hydrothermal system. The results also provide a baseline for tracking future changes in hydrothermal activity. (ii) The second case study corresponds to a monogenetic dome on Furnas volcano. Furnas volcano was chosen because the dome is currently cold and there has been no recent fumarolic activity. We wanted to see if the feeding conduit of the dome was associated with a conductive body that would represent the effect of alteration. (iii) The third case study corresponds to the summit area of Kîlauea volcano, which hosts an active lava lake and a vigorous geothermal system. In addition to the field data, we used 50 samples from Yellowstone, 3 samples from Furnas, and 21 samples from Kîlauea to further interpret the field data.

\subsection{Investigation of the northern boundary of the Yellowstone caldera}

The first dataset is located within the silicic volcanic province of Yellowstone National Park (Fig. 12). This volcanic province was shaped by several episodes of caldera formation (at $\sim 2.1 \mathrm{Ma}, \sim 1.3 \mathrm{Ma}$, and $\sim 0.64 \mathrm{Ma}$ ) associated with the deposition of ash flow tuffs and subsequent formation of massive rhyolitic and smaller basaltic lava flows (see Fig. 12 and also Christiansen, 2001). Seismic tomography by Huang et al. (2015) indicates the presence of partial melt reservoirs in the upper and lower crust beneath Yellowstone National Park, that provide the heat for its well-developed and complex hydrothermal system. This system displays at the surface both liquid-dominated, neutral to basic thermal areas, typically located at low elevation and vapor-dominated. In addition, we have acid-sulfate thermal areas located in topographically high areas along the boundary of the 0.64 Ma Yellowstone caldera (e.g., Fournier, 1989). In these later areas, steam and heat rise from deep boiling waters and either condense beneath a low permeability cap layer and then descend down fractures (heat pipes), or discharge through fumaroles either to the atmosphere or into pools (White et al., 1971; Pasquet et al., 2016).

To better understand the geometry of the ascending vapor plumes and their relation to geologic structures, an electrical conductivity survey was carried in the Solfatara Plateau vapor-dominated thermal area along the northern boundary of the Yellowstone caldera (Fig. 13). This area is located at an elevation of $\sim 2500 \mathrm{~m}$ on a massive rhyolite flow (Solfatara Plateau flow dated from $\sim 0.11 \mathrm{Ma}$ ) partially covered by glacial deposits of sandstones and conglomerates composed of altered rhyolite debris (Christiansen, 2001). At the time of the survey, the thermal area $(\sim 500 \times 500 \mathrm{~m})$, was displaying a small mud pool and several small fumaroles with visible native sulfur deposits.

The electrical conductivity survey was performed using a cable with a spacing of $10 \mathrm{~m}$ between the electrodes. The survey comprises 205

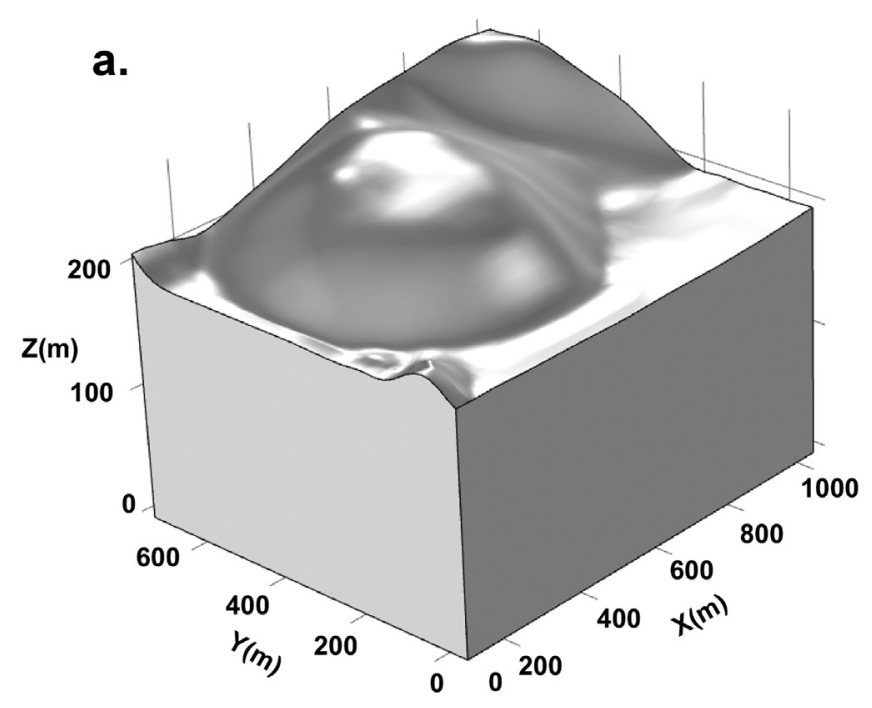

b.

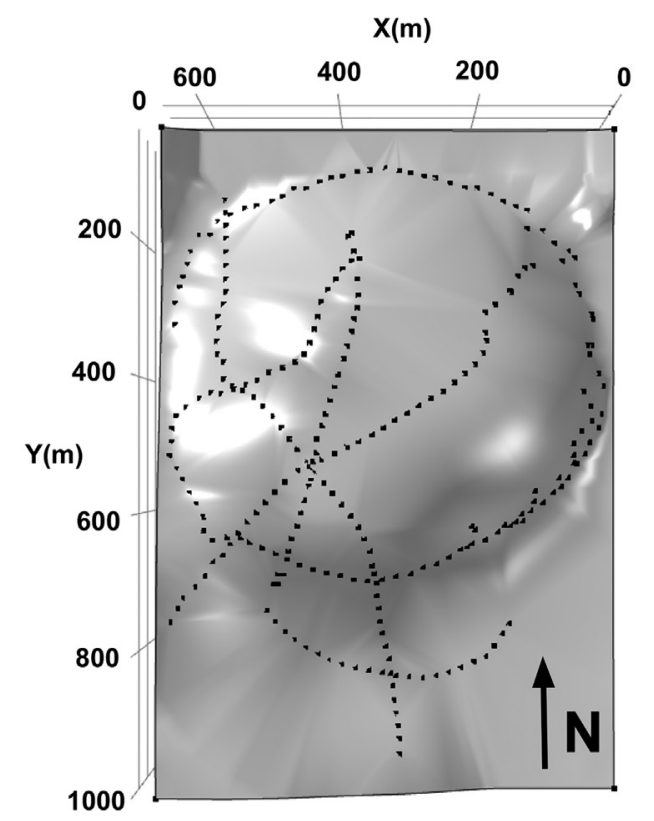

Fig. 20. Geometry of the 1630-monogenetic volcanic dome on Furnas volcano. a. 3D representation of the simulation domain. The topography close to the dome represents the tuff/pumice ring. b. Location of the electrodes. We used a 3D rendering of the observed topography with the force gradient superimposed grey shades. 


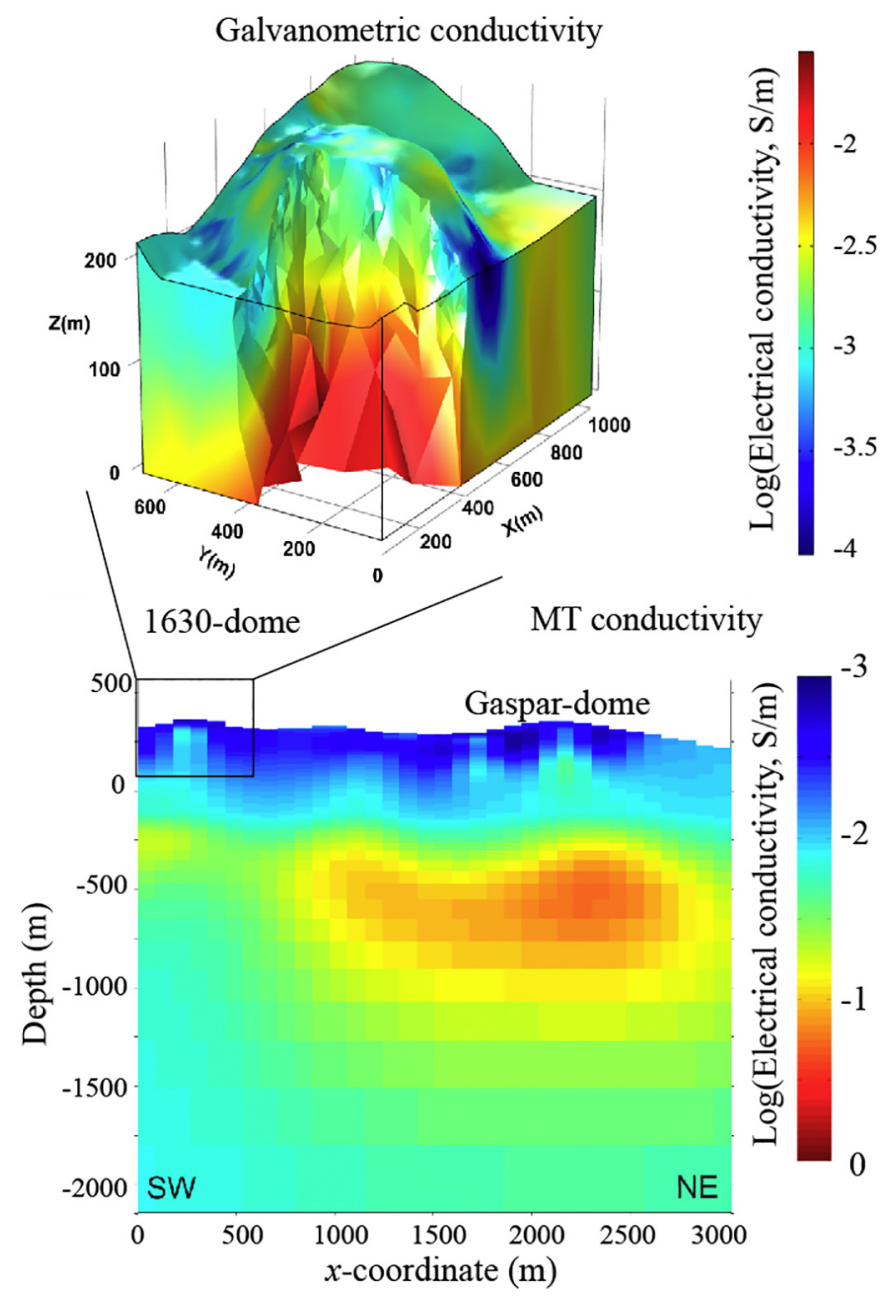

Fig. 21. Example of multiscale resistivity survey combining shallow galvanometric electrical conductivity data with deeper 3D conductivity imaging using the magnetotelluric (MT) method. The depth is referenced to the sea level. The upper figure shows the 3D electrical conductivity tomography of the 1630-monogenetic volcanic dome at Furnas volcano (São Miguel Island, Azores) using ECT-3D. Note the presence of localized conduit-like structures from the conductive body at depth and the monogenetic volcanic domes. The color scales were chosen for each dataset to maximize the information content of each given dataset.

electrodes, 352 resistance data, and the subsurface is discretized into 52,984 elements. The data were acquired along $2 \mathrm{D}$ lines and the data with a high standard deviation $(>10 \%)$ were removed from the considered dataset. The measurements were performed with an ABEM-LS instrument using the Wenner configuration. The topography and the position of the electrodes are shown in Figs. 13 and 14. The 3D inversion is shown in Fig. 15 and the algorithm has converged at iteration 5 (see Table 1). The electrical conductivity covers a broad range of values, from 0.1 to $10^{-4} \mathrm{~S} \mathrm{~m}^{-1}$.

In order to further interpret the field conductivity data, we performed laboratory experiments using $~ 50$ cores drilled in samples collected in the field (see location in Fig. 13) and from drill holes Y2 and Y8 drilled in YNP in the 60s (see location on Fig. 12, White et al., 1975). Fig. 16 shows how the conductivity of two core samples changes with the conductivity of the pore water. The samples have been fully brine-saturated under vacuum and left to rest for several weeks before performing the measurements. We observe that the data conform to the linear trend predicted by Eq. (1). Fitting the data with Eq. (1) yields a value, for each sample, of the (intrinsic) formation factor and surface conductivity. The CEC was measured with the cobalthexamine method. The petrophysical results are shown in Figs. 17 and 18. In Fig. 17, we show that the formation factor is related to the porosity by a power- law relationship and the surface conductivity is controlled by the cation exchange capacity. More precisely and despite some scatter in the data at low CEC-values, the relation between the surface conductivity $\sigma_{S}$ and the normalized cation exchange capacity, $C E C / F \phi$, is fairly consistent with the data. The slope of this trend $b$ (defined by $\sigma_{S}=b C E C / F \phi$ ) is observed to be $1.4 \times 10^{-5} \mathrm{~kg} \mathrm{~m}^{-1} \mathrm{~s}^{-1} \mathrm{~V}^{-1}$ consistent with the value given in Section $2\left(1.2 \times 10^{-5} \mathrm{~kg} \mathrm{~m}^{-1} \mathrm{~s}^{-1} \mathrm{~V}^{-1}\right)$. Comparing the surface conductivity data of the most altered samples (Fig. 17) to the field data, we can see that the surface conductivity can easily explain the high conductivity path observed in the electrical conductivity tomogram.

The spatial variations of conductivities observed in the model represented on Fig. 15 reflect variations in the lithology and in fluid saturation associated to the hydrothermal system. The lowest conductivity (close to $10^{-4} \mathrm{~S} \mathrm{~m}^{-1}$ ) is observed in the Eastern part of the survey. In other areas, where glacial deposits are outcropping conductivity values range from about $5 \times 10^{-3}$ to $0.1 \mathrm{~S} \mathrm{~m}^{-1}$. The largest values of conductivity are observed within a conduit beneath the location of the mud-pool and the fumaroles. Within this conduit, the conductivity is larger than the surface conductivity measured on glacial deposit samples ( $4 \times$ $10^{-4}$ to $10^{-2} \mathrm{~S} \mathrm{~m}^{-1}$ ) collected in the survey area (see Fig. 13 for the sample location) and on rhyolite flows $\left(3 \times 10^{-3}\right.$ to $\left.2 \times 10^{-2} \mathrm{~S} \mathrm{~m}^{-1}\right)$ from drill holes Y2 and Y8 (see Fig. 12 for the drill hole location) which are however outside the study area and within different rhyolite flow units than the one beneath our survey. The conductivity of this conduit suggests the presence of a multi-phase thermal plume beneath the mud-pool.

In Fig. 18, we plot the conductivity of the rock samples from the test site together with the range of in situ conductivity values determined from the sulfate-rich hydrothermal waters from the Yellowstone National Park (see Lewis et al., 1998). Values of the Total Dissolved Solid (TDS) of the ground water are comprised between 155 and 2017 ppm ( $\mathrm{pH}$ between 2 and 4). The TDS in ppm is then converted to a pore water conductivity in $\mu \mathrm{S} / \mathrm{cm}$ using $\sigma_{w}=\mathrm{TDS} / 0.67$. We see clearly from this plot that the surface conductivity plays an important role in the overall electrical conductivity of the rocks from this area.

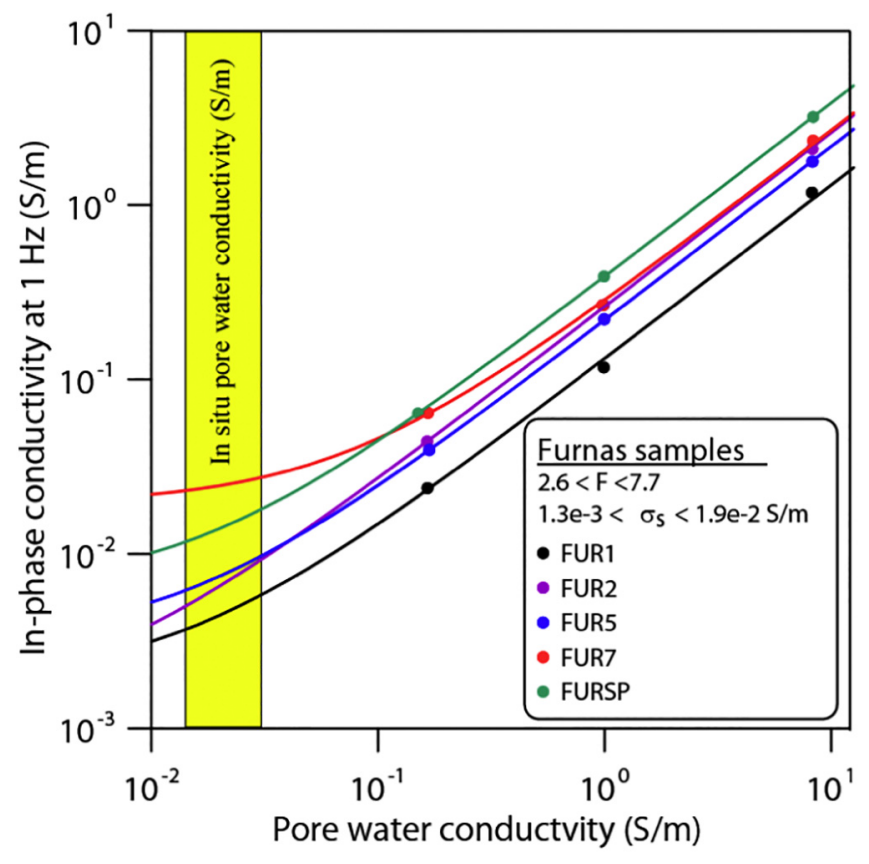

Fig. 22. Conductivity versus the pore water conductivity for the core samples from the Furnas. We have also shown (in yellow) the range of pore water conductivity (at $25^{\circ} \mathrm{C}$ ) for the meteoritic water in this area. 


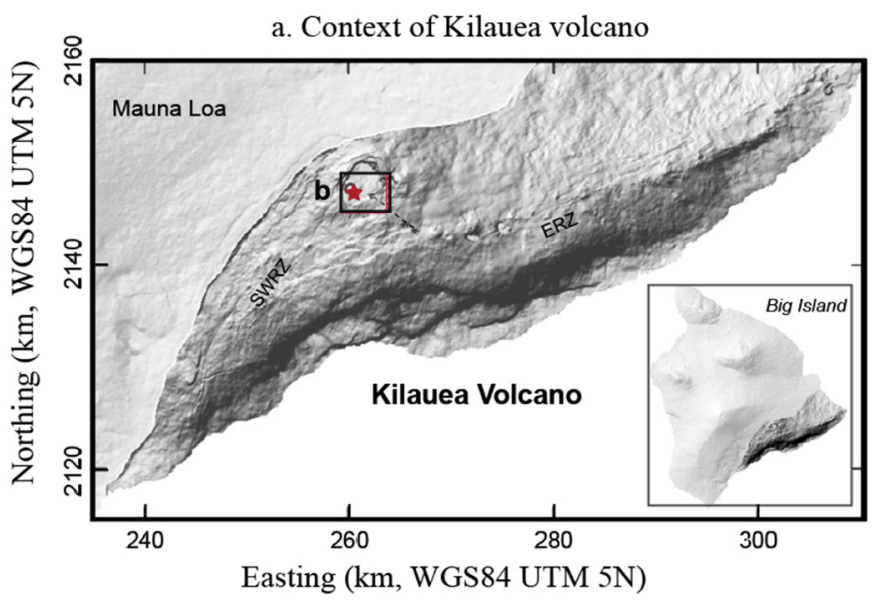

b. Context of Halema'uma'u pit crater

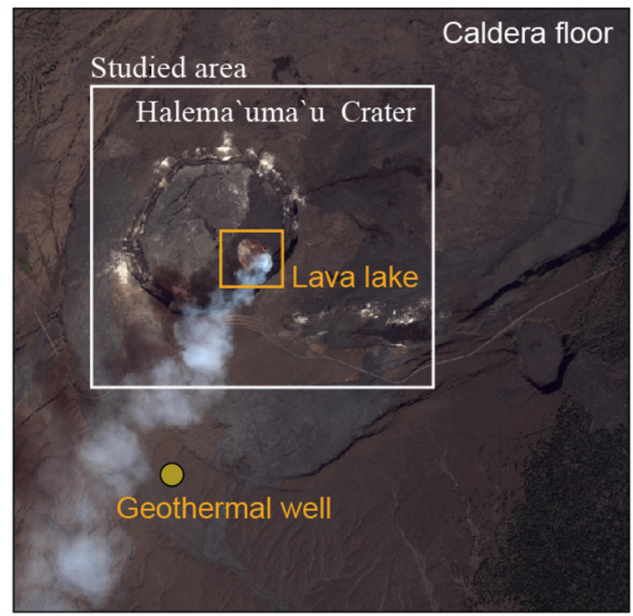

Fig. 23. Kīlauea volcano in Hawai'ii. a. General context of Kīlauea volcano in Hawai'ii. We used a 3D rendering of the observed topography with the force gradient superimposed grey shades. b. Google Earth extract on the summit caldera showing the lava lake (approximately $130 \mathrm{~m}$ in diameter), which formed in 2008 within the Halema'uma'u pit crater. We also show the position of the geothermal well from which the 21 samples have been extracted. ER stands for the East Rift Zone and SWRZ for the SouthWest Rift Zone.

\subsection{Study of a monogenetic dome on Furnas volcano}

Furnas volcano is a quiescent central volcano with caldera located in the Eastern side of São Miguel Island, the biggest and most populated island of the Azores volcanic archipelago. Located in the triple junction of the North America, Eurasia and Nubia tectonic plates (Searle, 1980), the Azores are crossed by numerous active tectonic structures with main WNW-ESE and NW-SE directions (Carmo et al., 2015; Madeira et al., 2015). In fact, one of the most important fracture systems identified at Furnas crosses the volcanic edifice with a WNW-ESE trend and shows a clear normal dip-slip component. Conjugate faults with $\mathrm{N}-\mathrm{S}$ and $(\mathrm{N})$ NE-(S)SW trends are well evident on the South flank of the volcano. Extensional fractures with NW-SE direction, parallel to the Terceira Rift regional fault system, are also possible to observe, as well as some EW faults suggested by the orientation of some valleys (Guest et al., 1999; Carmo et al., 2015). Furnas volcano comprises an impressive summit depression $5 \times 8 \mathrm{~km}$ wide formed by two nested calderas (Guest et al., 1999, 2015) and volcanic products up to 100,000 years BP were dated by Moore (1990) (Fig. 19).

Furnas volcanic activity has been characterized by several eruptive styles, ranging from mid-effusive activity to the caldera-forming explosive events (Guest et al., 1999, 2015). Ten intracaldera moderately explosive trachytic eruptions occurred in this volcano in the last 5000 years, two of which occurred in historical times (1439-43; 1630) (Guest et al., 2015). These historical subplinian/phreatomagmatic eruptions formed two tuff/pumice rings with central trachytic domes and its deposits mantle the caldera floor. The 1630 eruption was responsible for the death of about 200 persons mainly in the southern flank of the volcano. Gravity studies performed at São Miguel Island (Camacho et al., 1997; Montesinos et al., 1999) are consistent with low density magma bodies located at about 4-5 km depth below Furnas volcano, and minimum density values were also observed below Pico do Gaspar tuff ring, formed during the 1439-43 eruption, between 1 and $1.5 \mathrm{~km}$ depth (Camacho et al., 1997). A recent magnetotelluric study by Hogg et al. (2018) images an extended conductive body at the same location. Seismic tomography studies carried out in the central area of São Miguel Island agree with the gravimetric models indicating a P-wave low velocity zone at Furnas volcano that should extend $6 \mathrm{~km}$ below sea level (Zandomeneghi et al., 2008).

Nowadays volcanic activity at Furnas volcano is characterized by secondary manifestations of volcanism, which comprise low temperature fumaroles (95 to $100{ }^{\circ} \mathrm{C}$ ), steaming ground, thermal and cold $\mathrm{CO}_{2}$-rich springs, as well as soil diffuse degassing areas (e.g., Caliro et al., 2015; Viveiros et al., 2010; Silva et al., 2015). The caldera of Furnas volcano also contains several monogenetic trachytic domes in addition to the historical ones. Recent study carried out by Jeffery et al. (2016) indicate that Furnas trachytes are mainly derived from fractional crystallisation of alkali basalt parental magmas, at depths between
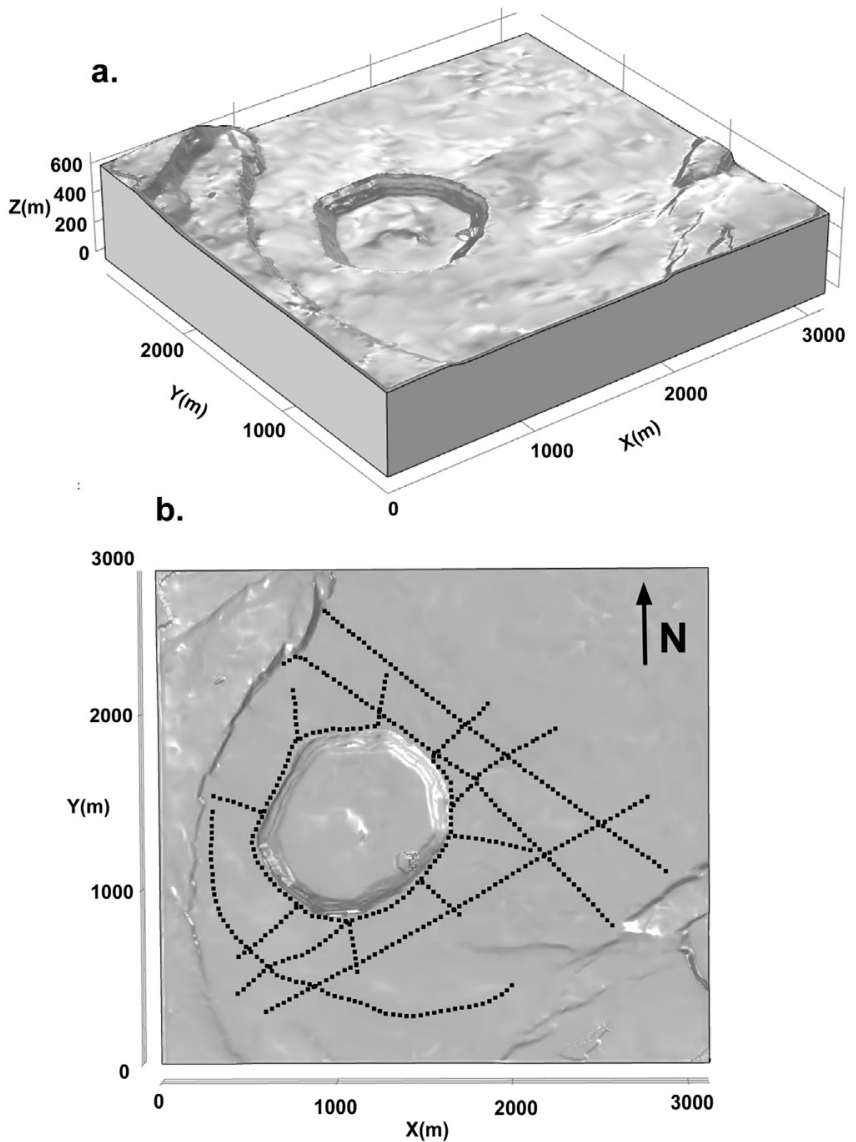

Fig. 24. Geometry of the summit area of Kîlauea volcano. a. 3D representation of the simulation domain. b. Location of the electrodes around the Halema'uma'u pit crater, which contains the lava lake. The profiles were organized to force the electrical current to go below the crater in order to probe the plumbing system of the lava lake. We used a $3 \mathrm{D}$ rendering of the observed topography with the force gradient superimposed grey shades. 
approximately 3 and $4 \mathrm{~km}$. Our goal in this paper is too see if the chimneys associated with these domes are characterized by a high conductivity because of the alteration of the surrounding materials, and for this the most recent formed trachytic dome will be used as study case.

The electrical conductivity survey was performed using a $1.26 \mathrm{~km}$ cable with a spacing of $20 \mathrm{~m}$ between the electrodes and 64 electrodes along the cable. The survey comprises 268 electrodes, 1688 resistance data (acquired long the 2D lines), and the subsurface is discretized with 53,111 elements. The data were acquired with the Wenner-alpha array along 2D profiles (typically 472 measurements with 64 electrodes). Data of poor quality (negative apparent resistivity data and data with standard deviation $>10 \%$ were removed from the dataset). The contact resistances were decreased using salty water at the position of the electrodes. The topography and electrodes array are shown in Fig. 20. The measurements were performed with an ABEM-SAS1000 instrument using the Wenner- $\alpha$ array. The tomography is shown in Fig. 21 (upper part) and displays conductivities in the range 003 to $10^{-4}$ $\mathrm{S} \mathrm{m}^{-1}$. Since the dome has cooled down, the high conductivity is here purely associated to the alteration of the volcanic rocks. Interestingly, the pore water in the hydrothermal system of Furnas volcano are only meteoritic waters (Caliro et al., 2015), so with a relatively low mineralization and conductivity. This implies in turn that the conductivity of the volcanic rocks is largely influenced by surface conductivity and therefore alteration.
In addition, Fig. 21 shows a comparison between the conductivity structure of the 1630-dome with a large scale survey based on magneto-telluric (MT). The survey was carried out by Hogg et al. (2018). In both cases, we see a more or less vertical conduit likely associated with alteration around the feeding conduit of the dome.

The average conductivity of the water measured at different sites of Furnas crater lake is $1.6 \times 10^{-2} \mathrm{~S} \mathrm{~m}^{-1}$ (see Andrade et al., 2016). Since the upper part of Furnas is saturated by meteoritic water, we think that this value can be considered as representative of the pore water conductivity in the upper part of Furnas. In Fig. 22, we plot the conductivity of the core samples from Furnas versus the brine conductivity together with the in situ range of pore water conductivity. It is clear that surface conductivity is expected to play a big role in the overall conductivity of the volcanic rocks at this site.

\subsection{Upper portion of the Kilauea caldera}

Sitting on the south-eastern slope of Mauna Loa Volcano on the Big Island in Hawai'i, Kīlauea volcano (Fig. 23), is one of the most documented and active volcano in the world. Presently in a shield-building stage, it is characterized by two rift zones, one intensely active to the east (East Rift Zone, ERZ) and the other, less frequently active, to the southwest (South West Rift Zone, SWRZ), diverging both from a caldera $4.5 \times 2.5 \mathrm{~km}$ in diameter, at an altitude of $1200 \mathrm{~m}$. Within this caldera,
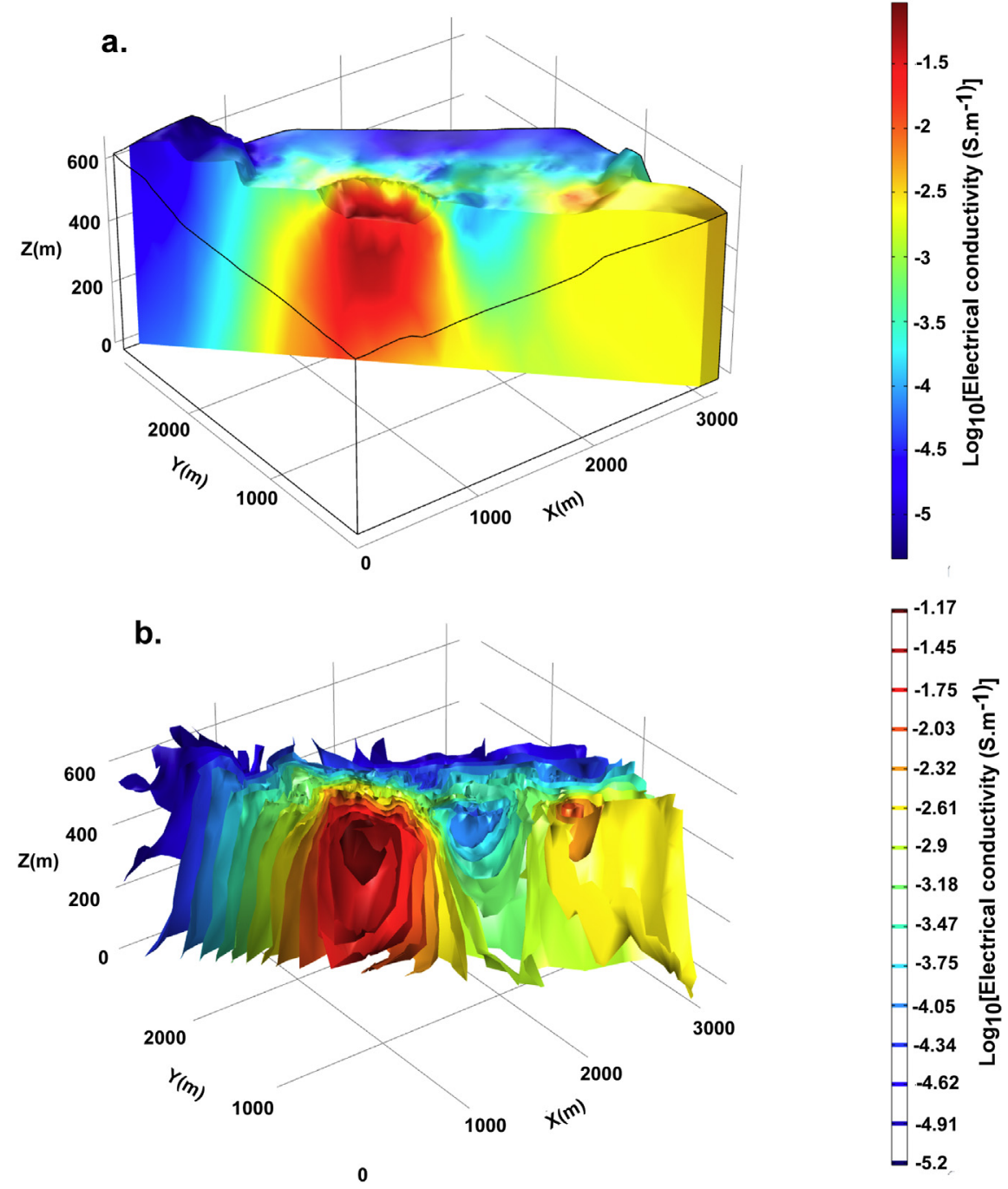

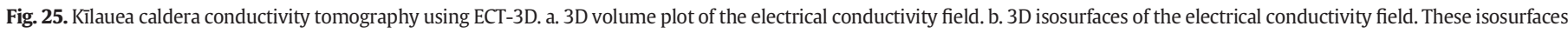

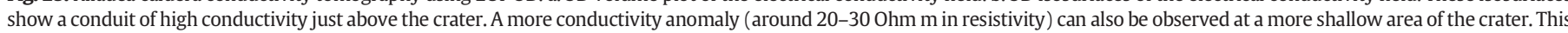
may possibly correspond to the feeding system of the lava lake and the alteration around the magmatic conduits. 


\section{Hawaii dataset}
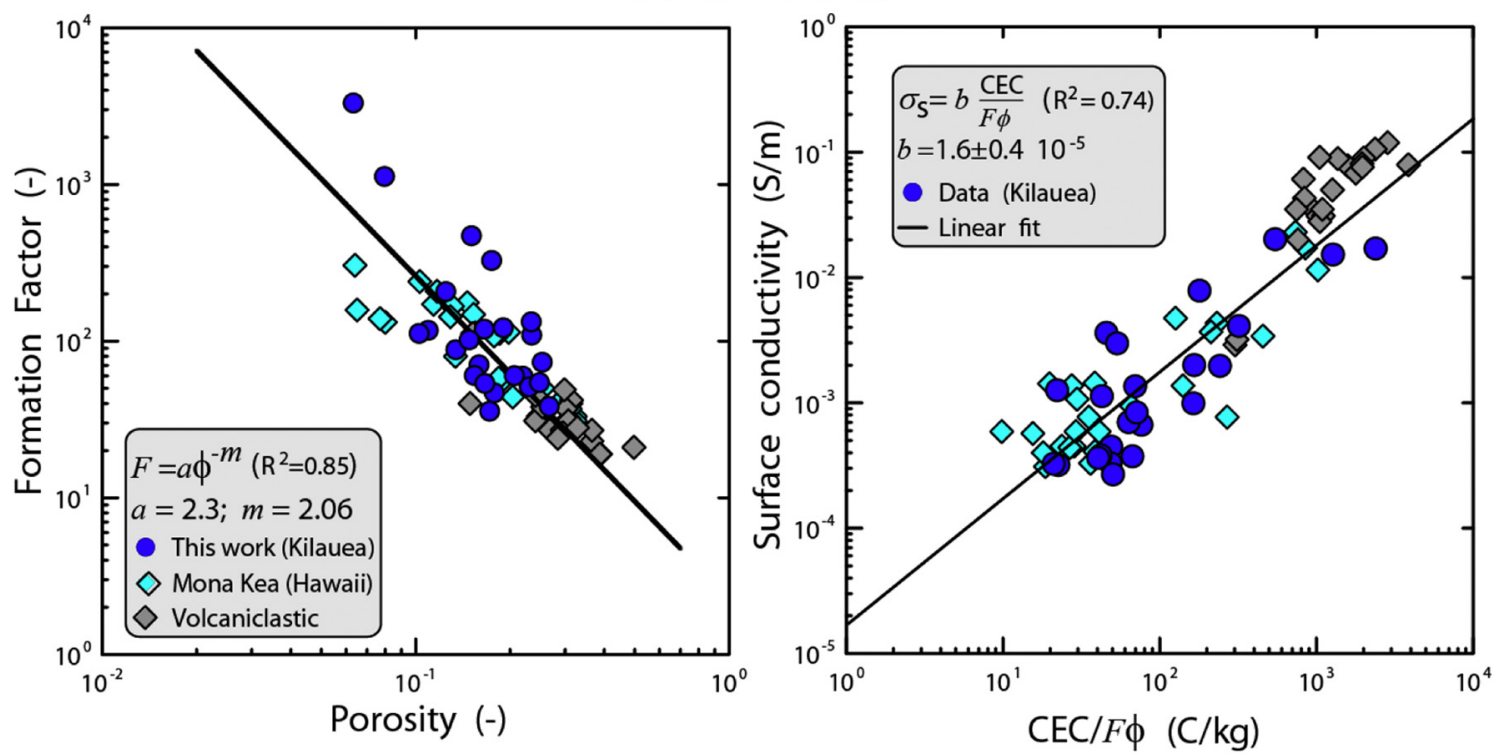

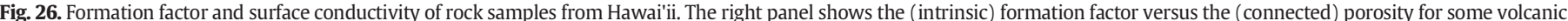

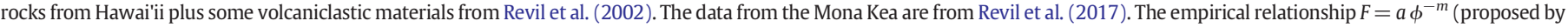

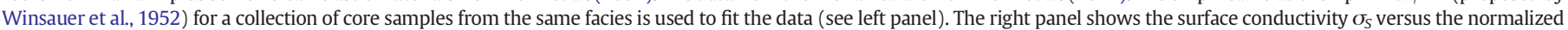

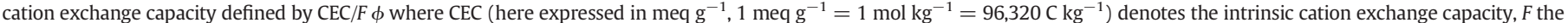
(intrinsic) formation factor, and $\phi$ the connected porosity. Measurements reported at $10 \mathrm{~Hz}$.

the Halema'uma'u pit crater ( $1 \mathrm{~km}$ in diameter), formed in the mid 1800 's (Fig. 23b).

In terms of composition, most of its surface is covered with homogeneous tholeiitic lava (Wolfe and Morris, 1996). Holcomb et al. (1986) have established, mostly using paleomagnetic measurements, that $70 \%$ of Kîlauea surface is younger than 500 years and $90 \%$ younger than

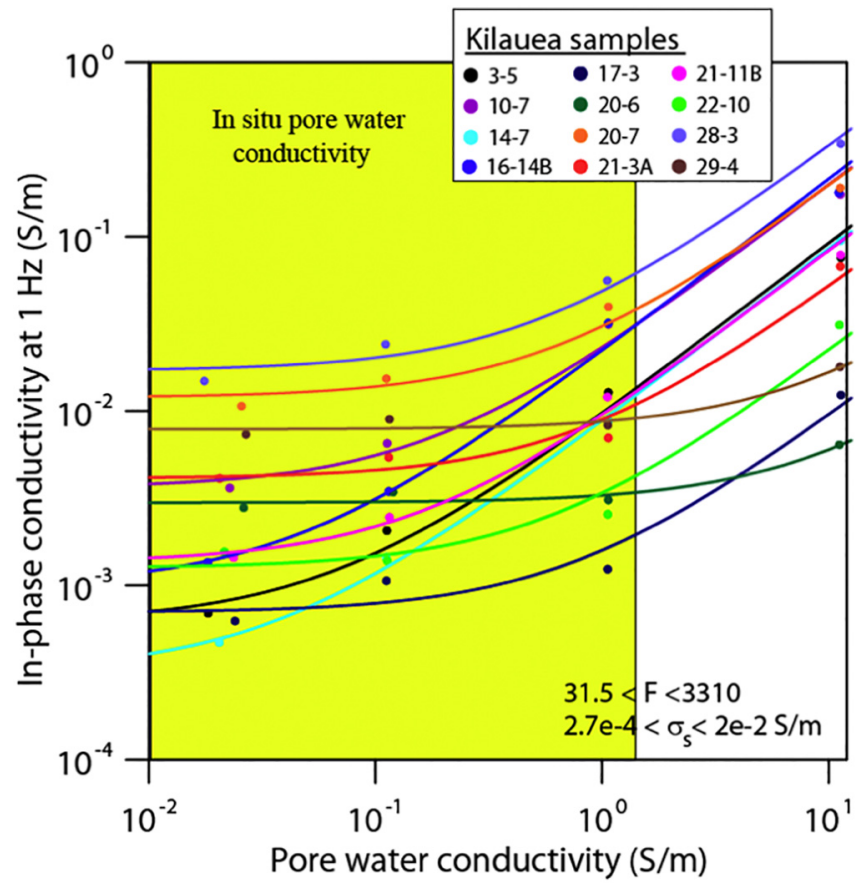

Fig. 27. Conductivity versus the pore water conductivity for the core samples from Kilauea We have also shown (in yellow) the range of pore water conductivity (at $25^{\circ} \mathrm{C}$ ). It is clear that the alteration of the basalts and the in situ range of pore water conductivity implies that in this case the rock conductivity is dominated by the surface conductivity.
1100 years. Kîlauea activity is marked by a complex history with both effusive and explosive cycles (Swanson et al., 2014). The present caldera dates from the 18th century, but was preceded by at least one earlier caldera that developed about 1500 years BP and was subsequently filled by common effusive activity (Swanson et al., 2012).

Activity is currently concentrated 1) along the ERZ, and 2) in the Halema'uma'u crater, which is hosting, since 2008, a continuously active lava lake $\sim 130 \mathrm{~m}$ in diameter (Fig. 23b). Activity at this vent has since been marked by variations in the depth of the magma column, sustained outgassing, small explosions at its surface emitting Pele's hairs, spatters and, less frequently, large explosions triggered by collapse of the walls of the crater in the lake (e.g., Wooten et al., 2009; Patrick and Witzke, 2011; Orr et al., 2013). The upper part of magma column is highly vesiculated as suggested by both gravity (Poland and Carbone, 2016; Carbone et al., 2013) and sample studies (Carey et al., 2012; Gailler et al. in prep). The geometry of the magma column is difficult to determine at depth. Another feature of the summit area is the presence of extensive and vigorous hydrothermal activity. It is marked at the surface by alteration areas, persistent fumaroles (Macdonald et al., 1983) and thermal anomalies (Patrick and Witzke, 2011). The hydrothermal activity is mostly concentrated along the buried limits of the previous caldera, eruptive fissures and in Halema'uma'u pit crater. The water table is located at $490 \mathrm{~m}$ below the caldera floor (Keller et al., 1979), reaching probably its highest level during the past few hundred years (Hurwitz et al., 2002, 2003).

Kîlauea volcano therefore offers a unique opportunity to study in detail the magmatic and hydrothermal systems in terms of extent or geometry, as well as their interactions. In this context, a large geophysical survey was carried out in 2015 within the caldera close to the lava lake. The electrical conductivity tomography survey was carried out using a $2.50 \mathrm{~km}$ cable with a spacing of $40 \mathrm{~m}$ between the electrodes and 64 electrodes along the cable. The survey comprises 465 electrodes (see position in Fig. 24), $N=3859$ resistance data, and the subsurface is discretized with $M=58,918$ elements (Table 1 ). The data acquisition is done along the lines and all the data are then inverted in 3D. The contact resistances were decreased by using both salty water and clays at the position of the electrodes. The measurements were performed with an 
ABEM-SAS4000 instrument using the Wenner- $\alpha$ array. The tomogram is shown in Fig. 25. The conductivity covers on a very broad range of values from $10^{-1}$ to $10^{-5} \mathrm{~S} \mathrm{~m}^{-1}$. The most conductive area is located below the crater probably around the magmatic conduit feeding the lava lake. The rocks around the conduit are probably very altered and the temperature increases also the conductivity. At the opposite, fresh basalts near the surface and in some deeper parts of the system show very low conductivity on the order of $10^{-5} \mathrm{~S} \mathrm{~m}^{-1}$.

Here again, in order to better interpret the field data, we conducted experimental resistivity data on 21 samples, measuring the conductivity to four brine salinities to determine the intrinsic formation factors and surface conductivities of the core samples. The core samples are from a 1262 m-deep borehole drilled on the summit of Kîlauea in 1973 and located approximately $1 \mathrm{~km}$ south of the edge of Halema'uma'u crater (Keller et al., 1979, see Fig. 23). The rock corresponds to olivine basalt, with minor amounts of olivine diabase, picrite diabase, and olivinepoor basalt. The basalts from the upper half of the well are relatively fresh, whereas they are quite altered below $\sim 480 \mathrm{~m}$.

The petrophysical data are reported in Figs. 26 and 27. We see that the fit provided by the relationship $F=a \phi^{-m}$ (Winsauer et al., 1952) is consistent with the previous datasets with $a \approx 2.3$ and $m \approx 2.0$. The surface conductivity $\sigma_{S}$ is proportional to the ratio $\mathrm{CEC} / \mathrm{F} \phi$. The slope of this linear trend $b$ is observed to be $1.6 \times 10^{-5} \mathrm{~kg} \mathrm{~m}^{-1} \mathrm{~s}^{-1} \mathrm{~V}^{-1}$ slightly higher than the value given in Section $2\left(1.2 \times 10^{-5} \mathrm{~kg} \mathrm{~m}^{-1}\right.$ $\left.\mathrm{s}^{-1} \mathrm{~V}^{-1}\right)$. As shown in Fig. 26, the electrical conductivity of altered volcanoclastic materials can be higher than $0.1 \mathrm{~S} \mathrm{~m}^{-1}$ (and higher at higher temperatures). It is therefore clear from these experimental data that the high conductivity below the Halema'uma'u crater can be largely explained by the effect of alteration as shown in Fig. 27. In this figure, the range of conductivity of the pore waters in $t$ upper of Kiluea are from McMurtry et al. (1977), Tilling and Jones (1991), and Evans et al. (2015) with a typical range of pore water conductivity between 1 $\times 10^{-2}$ to $2.6 \mathrm{~S} \mathrm{~m}^{-1}$ ( $\mathrm{pH}$ between 7.6 and 8.7 ).

\section{Discussion and future directions}

The conductivity of volcanic edifices is difficult to interpret because electrical conductivity depends on a broad number of parameters including two rock properties (the porosity and the cation exchange capacity), two properties of the pore water (the salinity and the saturation) and finally the temperature. In addition, the effect of the $\mathrm{pH}$ may change the cation exchange capacity and this may have an effect on the surface conductivity as well. This makes the interpretation of electrical resistivity tomograms a difficult exercise. This has been also the source of much confusion in the literature regarding the use and abuse of Archie's law without taking in proper consideration the effect of surface conductivity and alteration. To illustrate this point, we come back to the Killauea case study. Our conclusions contradict the analysis made by Keller et al. (1979) who used Archie law without any consideration for the effect of surface conductivity. They came to the conclusion that the cementation exponent $m$ was close to 0.9 (a value physically impossible since $m>1$ ) and that the shallow aquifers were filled with brackish water with a higher salinity than sea water. Considering that the conductivity of the rock is controlled by surface conductivity and assuming $F=a \phi^{-m}$ (see Winsauer et al., 1952), the conductivity is given by:

$\sigma \approx\left(\frac{b}{a}\right) \phi^{m-1} \mathrm{CEC}$

Now we see clearly that for a given level of alteration, the conductivity depends on the porosity at the power $\left(\mathrm{m}^{-1}\right)$. Therefore using $m=2$ (our study), we see that the conductivity depend on the porosity at the power 1 explaining therefore the exponent obtained by Keller et al. (1979) without using a physically unreasonable value of the cementation exponent.
In order to separate the conductivity associated with the pore water from the conductivity associated with the effect of alteration, electrical resistivity can also be measured in concert with another method called induced polarization. Induced polarization looks at the ability of the materials to get polarized in a low-frequency electrical field. Induced polarization complements electrical resistivity data in a variety of ways. The most obvious of them is the fact that surface conductivity and quadrature conductivity (the imaginary component of the complex conductivity) are proportional to each other. Therefore induced polarization tomography could be used to separate the bulk conductivity and the surface conductivity. In turn, this may have strong implications in volcanic areas to image alteration (see discussion in Revil et al., 2017, 2017). This will be discussed in a future contribution.

The second point we want to discuss is the use of techniques to improve the quality/resolution of the resistivity tomograms. New techniques have been indeed recently developed to merge prior geological information and geophysical resistivity data (Farquharson, 2008; Lelièvre and Oldenburg, 2009) or using joint inversion of geophysical data (Gallardo and Meju, 2004; Bouchedda et al., 2012). Along this line, it is worth mentioning the use of image guided inversion that use prior geological information to guide the inversion of the resistivity data using a locally-adapted regularization (e.g., a locally based roughness matrix) based on prior geological structures or seismic data (Zhou et al., 2014).

The future direction of electrical conductivity tomography is towards the $4 \mathrm{D}$ monitoring of volcanic structures. This involves the setup of permanent arrays of electrodes with independent galvanometric stations combined with magneto-telluric stations. The development of future arrays that would measure both the galvanometric and inductive responses of the Earth (involving the combined used of electrical dipoles, inductive loops, and the three components of the magnetic field) will be an asset for such monitoring. The data from such types of array could be inverted on a continuous basis and allow the forecast of near-future volcanic activity using data assimilation techniques such as those used in weather forecasting including the possibility to have bifurcation in the non-linear behavior of the system. The interpretation of such datasets would require also the coupling with multiphase flow modeling (see for instance Rinaldi et al., 2011, for some first steps in this direction). This could allow in turn the use of fully coupled inversion techniques such as those classically used in hydrogeophysics to determine the transport properties of shallow aquifers (Jardani et al., 2013).

\section{Conclusion}

The electrical conductivity of volcanic rocks typically vary over 4 or 5 orders of magnitude while the conductivity of magma bodies may vary over 6 orders of magnitude. Electrical conductivity tomography is a powerful technique when it comes to image volcanoes. Three examples are studied in this paper at different scales (few hundred meters to $2.5 \mathrm{~km}$ and a maximum depth of investigation of $600 \mathrm{~m}$ ). Unfortunately, electrical conductivity depends on too many parameters (salinity, water content, temperature and alteration) to make electrical resistivity tomography a stand-alone technique. The future of electrical conductivity tomography is in the use of a complementary method known as induced polarization, which can be recorded with the same instruments used for resistivity tomography. Finally, 4D monitoring of the conductivity change of active volcanoes could be used to forecast their activity especially temperature and saturation changes as well as damage and healing/sealing processes.

\section{Acknowledgements}

We acknowledge the support of the University of Melbourne through a project funded by the Commonwealth of Australia (contract CR-2016-UNIV.MELBOURNE-147672-UMR5275). The electrical conductivity data and field samples at Yellowstone were collected under 
the research permit YELL-2016-SCI-7006. S. Haas, S. Gunther, and park rangers at Yellowstone National Park are thanked for assistance with permitting and logistics. The drill-hole cores from Yellowstone were provided to us by the Core Research Center (CRC). We thank the staff of the CRC and P. Dobson for providing us help and information about the cores. Lidar data over Yellowstone study area are available at https://doi.org/10.5069/G99P2ZKK. These data were acquired and processed by the National Center for Airborne Laser Mapping (NCALM http://www.ncalm.org), funded by National Science Foundataion (NSF)'s Division of Earth Sciences, Instrumentation and Facilities Program (EAR-1043051) and were provided to us by the OpenTopography Facility also funded by NSF (Awards 1226353 \& 1225810). This research was also funded by Labex grant OSUG@2020 (ANR10 LABX56), the CNRS-INSU program SYSTER, and a CNRS-INSU project. The Kīlauea study was funded by a CNRS INSU project. We are grateful to T. Neal, J. Sutton, S. Swanson, S. Brantley and the HVO's staff in Hawai'i for their support. We also thank the HVO Park for its support and access authorization. We also acknowledge all the volunteers for their participation to the field data acquisition. We thank D. Thomas, J. Kauahikaua, J.F. Lénat, S. Hurwitz, and J. Vandemeulebrouck, and C. Bouligand for fruitful discussions, and S. Roques for her help with the petrophysical measurements. The Volcanological Survey of Indonesia, more particularly A. B. Santoso and G. Suantika, are thanked for their help with the collection of some core samples in Indonesia. M.J. Heap thanks the Buttle Family, Pee Jay tours, GNS Science, and all those that helped in the collection of the samples from Whakaari/White Island. We also thank B. Ritzinger for his help in the preparation of the cores from Yellowstone. Finally, we thank the Editor and the two referees for their work and very constructive comments

\section{References}

Al Hagrey, S.A., 2007. Geophysical imaging of root-zone, trunk, and moisture heterogeneity. J. Exp. Bot. 58 (4):839-854. https://doi.org/10.1093/jxb/erl237.

Andrade, C., Viveiros, F., Cruz, J.V., Coutinho, R., Siva, C., 2016. Estimation of the $\mathrm{CO}_{2}$ flux from Furnas volcanic Lake (São Miguel, Azores). J. Volcanol. Geotherm. Res. 315: 51-64. https://doi.org/10.1016/j.jvolgeores.2016.02.005.

Archie, G.E., 1942. The electrical resistivity log as an aid in determining some reservoir characteristics. Petroleum Trans. AIME 146, 54-62.

Barde-Cabusson, S., Bolós, X., Pedrazzi, D., Lovera, R., Serra, G., Martí, J., Casas, A., 2013. Electrical resistivity tomography revealing the internal structure of monogenetic volcanoes. Geophys. Res. Lett. 40:2544-2549. https://doi.org/10.1002/grl.50538.

Bernard, M.-L, Zamora, M., Géraud, Y., Boudon, G., 2007. Transport properties of pyroclastic rocks from Montagne Pelée volcano (Martinique, Lesser Antilles). J. Geophys. Res. 112:B05205. https://doi.org/10.1029/2006JB004385.

Binley, A., Cassiani, G., Middleton, R., Winship, P., 2002. Vadose zone flow model parameterization using cross-borehole radar and resistivity imaging. J. Hydrol. 267: 147-159. https://doi.org/10.1029/2011WR010409.

Bolève, A., Crespy, A., Revil, A., Janod, F., Mattiuzzo, J.L., 2007. Streaming potentials of granular media: influence of the Dukhin and Reynolds numbers. J. Geophys. Res. 112: B08204. https://doi.org/10.1029/2006]B004673.

Bonnet, A.-L., Corriveau, L., 2007. Alteration vectors to metamorphosed hydrothermal systems in gneissic terranes. In: Goodfellow, W.D. (Ed.), Mineral Deposits of Canada-A Synthesis of Major Deposit-Types, District Metallogeny, the Evolution of Geological Provinces, and Exploration Methods. Geological Association of Canada, Mineral Deposits Division, pp. 1035-1049 Special Publication No. 5.

Börner, F.D., 1992. Complex conductivity measurements of reservoir properties. Proceedings of the Third European Core Analysis Symposium, Paris, pp. 359-386.

Bouchedda, A., Chouteau, M., Binley, A., Giroux, B., 2012. 2-D joint structural inversion of cross-hole electrical resistance and ground penetrating radar data. J. Appl. Geophys. 78, 52-67.

Broyden, C.G., 1965. A class of methods for solving nonlinear simultaneous equations. Math. Comput. 19, 577-593.

Brunauer, S., Emmett, P.H., Teller, E., 1938. Adsorption of gasses in multimolecular layers. J. Am. Chem. Soc. 60 (2):309-319. https://doi.org/10.1021/ja01269a023.

Byrdina, S. Friedel, S. Vandemeulebrouck, J., Budi-Santoso, A. Suryanto, W., Rizal, M.H.. Winata, E., 2017. Geophysical image of the hydrothermal system of Merapi volcano. J. Volcanol. Geotherm. Res. 329:30-40. https://doi.org/10.1016/j.jvolgeores.2016.11.011.

Caliro, S., Viveiros, F., Chiodini, G., Ferreira, T., 2015. Gas geochemistry of hydrothermal fluids of the S. Miguel and Terceira Islands, Azores. Geochim. Cosmochim. Acta 168 43-57. https://doi.org/10.1016/j.gca.2015.07.009.

Camacho, A.G., Montesinos, F.G., Vieira, R., 1997. A three-dimensional gravity inversion applied to São Miguel Island (Azores). J. Geophys. Res. 102 (B4), 7717-7730.

Carbone, D., Poland, M.P., Patrick, M.R., Orr, T.R., 2013. Continuous gravity measurements reveal a low-density lava lake at Kĩlauea volcano, Hawai'i. Earth Planet. Sci. Lett. 376: 178-185. https://doi.org/10.1016/j.epsl.2013.06.024.
Carey, R.J., Manga, M., Degruyter, W., Swanson, D., Houghton, B., Orr, T., Patrick, M., 2012. Externally triggered renewed bubble nucleation in basaltic magma: the 12 October 2008 eruption at Halema'uma'u Overlook vent, Kīlauea, Hawai'i, USA. J. Geophys. Res. 117:B11202. https://doi.org/10.1029/2012JB009496.

Carmo, R., Madeira, J., Ferreira, T., Queiroz, G., Hipólito, A., 2015. Volcano-tectonic structures of S. Miguel Island, Azores. In: Gaspar, J.L., Guest, J.E., Duncan, A.M., Barriga, F. J.A.S., Chester, D.K. (Eds.), Volcanic Geology of São Miguel Island (Azores Archipelago). vol. 44. Geological Society of London Memoir:pp. 65-86. https://doi.org/ $10.1144 / \mathrm{M} 44.6$

Christiansen, R.L., 2001. The Quaternary and Pliocene Yellowstone Plateau volcanic field of Wyoming, Idaho, and Montana. US Geol. Surv. Prof. Pap. 729-G.

Churcher, R.L., French, P.R., Shaw, J.C., Schramm, L.L., 1991. Paper SPE 21041 Presented at the 1991 Int. Symp. On Oilfield Chemistry, Anaheim, February 20-22, 1991.

Ciesielski, H., Sterckeman, T., Santerne, M., Willery, J.P., 1997. Determination of cation exchange capacity and exchangeable cations in soils by means of cobalt hexamine trichloride. Effects of experimental conditions. Agronomie, EDP Sciences 17 (1), 1-7.

Comparon, L., 2005. Etude expérimentale des propriétés électriques et diélectriques des matérieux argileux consolidés. PhD Thesis. Institut de Physique du Globe de Paris, p. 400.

Cremers, A., Van Loon, J., Laudelout, H., 1966. Geometry effects for specific electrical conductance in clays and soils. In: Biley, S.W. (Ed.), Clays and Clay Minerals. Proceeding of the 14th National Conference, Berkeley, California. Pergamon Press, Oxford Edited by.

De Groot-Hedlin, C., Constable, S., 1990. Occam's inversion to generate smooth, two-dimensional models from magnetotelluric data. Geophysics 55 (12), 1613-1624.

Deutsch, C., Journel, A., 1992. GSLIB: Geostatistical software library and user’s guide. Oxford University Press, New York.

Evans, W.C., Bergfeld, D., Sutton, A.J., Lee, R.C., Lorenson, T.D., 2015. Groundwater chemistry in the vicinity of the Puna Geothermal Venture power plant, Hawai'i, after two decades of production. US Geol. Surv. Sci. Investig. Rep. 2015-5139:26. https://doi.org/ $10.3133 /$ sir20155139.

Farquharson, C.G., 2008. Constructing piecewise-constant models in multidimensional minimum-structure inversions. Geophysics 73, K1-K9.

Fikos, I., Vargemezis, G., Zlotnicki, J., Puertollano, J.R., Alanis, P.B., Pigtain, R.C., Villacorte, E. U., Malipot, G.A., Sasai, Y., 2012. Electrical resistivity tomography study of Taal volcano hydrothermal system, Philippines. Bull. Volcanol. 74 (8), 1821-1831.

Finizola, A., Revil, A., Rizzo, E., Piscitelli, S., Ricci, T., Morin, J., Angeletti, B., Mocochain, L., Sortino, F., 2006. Hydrogeologic insights at Stromboli volcano (Italy) from geoelectrical, temperature, and $\mathrm{CO}_{2}$ soil degassing investigations. Geophys. Res. Lett. 33 (L17304). https://doi.org/10.1029/2006GL026842.

Finizola, A., Ricci, T., Deiana, R., Cabusson, S.B., Rossi, M., Praticelli, N., Giocoli, A., Romano, G., Delcher, E., Suski, B., 2010. Adventive hydrothermal circulation on Stromboli volcano (Aeolian Islands, Italy) revealed by geophysical and geochemical approaches: implications for general fluid flow models on volcanoes. J. Volcanol. Geotherm. Res. 196 (1), 111-119.

Fournier, R.O., 1989. Geochemistry and dynamics of the Yellowstone National Park hydrothermal system. Annu. Rev. Earth Planet. Sci. 17, 13-53.

Gaillard, F., 2004. Laboratory measurements of electrical conductivity of hydrous and dry silicic melts under pressure. Earth Planet. Sci. Lett. 218 (1-2):215-228. https://doi, org/10.1016/S0012-821X(03)00639-3.

Gaillard, F., Malki, M., lacono-Marziano, G., Pichavant, M., Scaillet, B., 2008. Carbonatite melts and electrical conductivity in the asthenosphere. Science 322.

Gallardo, L.A., Meju, M.A., 2004. Joint two-dimensional DC resistivity and seismic traveltime inversion with cross-gradients constraints. J. Geophys. Res. 109:B03311. https://doi.org/10.1029/2003JB002716.

Galley, A.G., Hannington, M., Jonasson, I., 2007. Volcanogenic massive sulphide deposits. In: Goodfellow, W.D. (Ed.), Mineral Deposits of Canada-A Synthesis of Major Deposit-types, District Metallogeny, the Evolution of Geological Provinces, and Exploration Methods. Geological Association of Canada, Mineral Deposits Division, pp. 141-161 Special Publication 5.

Gibson, H.L. Galley, A.G. 2007. Volcanogenic massive sulphide deposits of the Archean, Noranda district, Québec. In: Goodfellow, W.D. (Ed.), Mineral Deposits of Canada-A Synthesis of Major Deposit-types, District Metallogeny, the Evolution of Geological Provinces, and exploraTion Methods. Geological Association of Canada, Mineral Deposits Division, pp. 533-552 Special Publication, 5.

Goes, B.J.M., Meekes, J.A.C., 2004. An effective electrode configuration for the detection of DNAPLs with electrical resistivity tomography. J. Environ. Eng. Geophys. 9:127-141. https://doi.org/10.4133/JEEG9.3.127.

Goodfellow, W.D., 2007. Metallogeny of the Bathurst mining camp, northern New Brunswick. In: Goodfellow, W.D. (Ed.), Mineral Deposits of Canada-A Synthesis of Major Deposit-types, District Metallogeny, the Evolution of Geological Provinces, and Exploration Methods. Geological Association of Canada, Mineral Deposits Division, pp. 449-469 Special Publication, 5.

Gresse, M., Vandemeulebrouck, J., Byrdina, S., Chiodini, G., Revil, A., Johnson, T.C., Ricci, T., Vilardo, G. Lebourg, T., Grangeon, J.. Bascou, P., Metral, L. 2017. 3-D resistivity tomography of the Solfatara crater (Italy): implication for the multiphase flow structure of the shallow hydrothermal system. J. Geophys. Res. 122. https://doi.org/10.1002/ 2017JB014389.

Guest, J., Gaspar, J.L., Cole, P., Queiroz, G., Duncan, A.M., Wallenstein, N., Ferreira, T., Pacheco, J., 1999. Volcanic geology of Furnas Volcano, São Miguel, Azores. J. Volcanol. Geotherm. Res. 92, 1-29.

Guest, J.E., Pacheco, J.M., Cole, P.D., Duncan, A.M., Wallenstein, N., Queiroz, G., Gaspar, J.L., Ferreira, T., 2015. The volcanic history of Furnas Volcano, São Miguel, Azores. In: Gaspar, J.L., Guest, J.E., Duncan, A.M., Barriga, F.J.A.S., Chester, D.K. (Eds.), Volcanic Geology of São Miguel Island (Azores Archipelago), Geological Society of London Memoir. vol. 44:pp. 125-134. https://doi.org/10.1144/M44.9. 
Günther, T., Rücker, C., Spitzer, K., 2006. Three-dimensional modelling and inversion of DC resistivity data incorporating topography-II. Inversion. Geophys. J. Int. 166 (2): 506-517. https://doi.org/10.1111/j.1365-246X.2006.03011.X.

Hansen, P.C., 1998. Rank-deficient and Discrete Ill-posed Problems: Numerical Aspects of Linear Inversion. Society for Industrial and Applied Mathematics (SIAM), Philadelphia https://doi.org/10.1137/1.9780898719697.

Hansen, P.C., O'Leary, D.P., 1993. The use of the L-curve in the regularization of discrete illposed problems, Society for Industrial and Applied Mathematics (SIAM). J. Sci. Comput. 14, 1487-1503.

Heap, M.J., Kennedy, B.M., Farquharson, J.I., Ashworth, J., Mayer, K., Letham-Brake, M., Reuschlé, T., Gilg, H.A., Scheu, B., Lavallée, Y., Siratovich, P., 2017. A multidisciplinary approach to quantify the permeability of the Whakaari/White Island volcanic hydrothermal system (Taupo Volcanic Zone, New Zealand). J. Volcanol. Geotherm. Res. 332, 88-108.

Heap, M.J., Kennedy, B.M., Pernin, N., Jacquemard, L., Baud, P., Farquharson, J.I., Scheu, B. Lavallée, Y., Gilg, H.A., Letham-Brake, M., Mayer, K., 2015. Mechanical behaviour and failure modes in the Whakari (White Island volcano) hydrothermal system, New Zealand. J. Volcanol. Geotherm. Res. 295, 26-42.

Hedenquist, J.W., Lowenstern, J.B., 1994. The role of magmas in the formation of hydrothermal ore deposits. Nature 370, 519-527.

Hogg, C., Kiyan, D., Rath, V., Byrdina, S., Vandemeulebrouck, J., Revil, A., Silva, C., Viveiros, F., Ferreira, T., Carmo, R., 2018. Three-dimensional interpretation of short period magnetotelluric data at Furnas Volcano, Azores Islands. Geophys. J. Int. 213: 371-386. https://doi.org/10.1093/gji/ggx512.

Holcomb, R.T., Champion, D., McWilliams, M., 1986. Dating recent Hawai'ian lava flows using paleomagnetic secular variation. Geol. Soc. Am. Bull. 97 (7):829-839. https:// doi.org/10.1130/0016-7606(1986)97.

Honnorez, J.J., Alt, J.C., Humphris, S.E., Herzig, P.M., Miller, D.J., Becker, K., et al., 1998. Vivisection and autopsy of active and fossil hydrothermal alterations of basalt beneath and within the TAG hydrothermal mound. In: Herzig, P.M., Humphris, S.E., Miller D.J., Zierenberg, R.A. (Eds.), TAG-Drilling an Active Hydrothermal System on a Sediment-Free Slow-Spreading Ridge, Site 957: Proceedings of the Ocean Drilling Program, Scientific Results. vol. 158, pp. 231-254.

Huang, H.H., Lin, F.C., Schmandt, B., Farrell, J., Smith, R.B., Tsai, V.C., 2015. The Yellowstone magmatic system from the mantle plume to the upper crust. Science 348 (6236), 773-776.

Huang, X., Xu, Y., Karato, S.-I., 2005. Water content in the transition zone from electrical conductivity in wadsleyite and ringwoodite. Nature 434, 746-749.

Hurwitz, S., Goff, F., Janik, C.J., Evans, W.C., Counce, D.A., Sorey, M.L., Ingebritsen, S.E., 2003. Mixing of magmatic volatiles with groundwater and interaction with basalt on the summit of Kīlauea Volcano, Hawai'ii. J. Geophys. Res. B1:108. https://doi.org/ 10.1029/2001JB001594.

Hurwitz, S., Ingebritsen, S.E., Sorey, M.L., 2002. Episodic thermal perturbations associated with groundwater fl ow: an example from Kīlauea Volcano, Hawai'ii. J. Geophys. Res. 107 (B11). https://doi.org/10.1029/2001JB001654.

Jardani, A., Revil, A., Bolève, A., Dupont, J.P., 2008. 3D inversion of self-potential data used to constrain the pattern of ground water flow in geothermal fields. J. Geophys. Res. 113:B09204. https://doi.org/10.1029/2007JB005302.

Jardani, A., Revil, A., Dupont, J.P., 2013. Stochastic joint inversion of hydrogeophysical data for salt tracer test monitoring and hydraulic conductivity imaging. Adv. Water Resour. 52:62-77. https://doi.org/10.1016/j.advwatres.2012.08.005.

Jeffery, A.J., Gertisser, R., Driscoll, B.O., Pacheco, J., Whitley, S., Pimentel, A., Self, S., 2016. Temporal evolution of a post-caldera, mildly peralkaline magmatic system: Furnas Volcano, São Miguel. Azores. Contrib. Mineral. Petrol. 171 (42). https://doi.org/ 10.1007/s00410-016-1235-y.

Johnson, T.C., Versteeg, R.J., Ward, A., Day-Lewis, F.D., Revil, A., 2010. Improved hydrogeophysical characterization and monitoring through parallel modeling and inversion of time-domain resistivity and induced-polarization data. Geophysics 75 (4): WA27-WA41. https://doi.org/10.1190/1.3475513.

Kaufhold, S., Dohrmann, R., Klinkenberg, M., Siegesmund, S., Ufer, K., 2010. N2-BET specific surface area of bentonites. J. Colloid Interface Sci. 349:275-282. https://doi.org/ $10.1016 /$ j.jcis.2010.05.018.

Keller, G.V., Trowbridge, G.L., Murray, J.C., Skokan, C.K., 1979. Results of an experimental drill hole at the summit of Kîlauea volcano, Hawai'ii. J. Volcanol. Geotherm. Res. 5 (3-4):345-385. https://doi.org/10.1016/0377-0273(79)90024-6.

Key, K., 2016. MARE2DEM: a 2-D inversion code for controlled-source electromagnetic and magnetotelluric data. Geophys. J. Int. 207 (1):571-588. https://doi.org/10.1093/ gji/ggw290.

Koestel, J., Vanderborght, J., Javaux, M., Kemna, A., Binley, A., Vereecken, H., 2009. Noninvasive 3-D transport characterization in a sandy soil using ERT: 2, transport process inference. Vadose Zone J. 8:723-734. https://doi.org/10.2136/vzj2008.0154.

Kurniawan, B., 2005. Shaly Sand Interpretation Using CEC-Dependent Petrophysical Parameters. PhD Thesis. Louisiana State University, p. 201.

Lelièvre, P.G., Oldenburg, D.W., 2009. A comprehensive study of including structural orientation information in geophysical inversions. Geophys. J. Int. 178, 623-637.

Lewis, A.J., Komninou, A., Yardley, B.W.D., Palmer, M.R., 1998. Rare earth element speciation in geothermal fluids from Yellowstone National Park, Wyoming, USA. Geochim. Cosmochim. Acta 62 (4), 657-663.

Lima, A.T., Loch, J.P.G., Kleingeld, P.J., 2010. Bentonite electrical conductivity: a model based on series-parallel transport. J. Appl. Electrochem. 40:1061-1068. https://doi. org/10.1007/s10800-009-0060-7.

Linde, N., Revil, A., 2007. A comment on "Electrical tomography of La Soufrière of Guadeloupe Volcano: Field experiments, 1D inversion and qualitative interpretation", by Nicollin, F. et al., (Earth Planet Sci. Lett. 244 (2006) 709-724). Earth Planet. Sci. Lett. 258:619-622. https://doi.org/10.1016/j.epsl.2006.02.020.

Lorne, B., Perrier, F., Avouac, J.-P, 1999. Streaming potential measurements. Properties of the electrical double layer from crushed rock samples. J. Geophys. Res. 104 (B8) $17,857-17,877$.
Macdonald, G.A., Abbott, A.T., Peterson, F.L., 1983. Volcanoes in the Sea: The Geology of Hawai'ii. Second Edition. University of Hawai'ii Press, Honolulu, p. 517.

Madeira, J., Brum da Silveira, A., Hipólito, A., Carmo, R., 2015. Active tectonics in the Central and Eastern Azores islands along the Eurasia-Nubia boundary: a review. In: Gaspar, J.L., Guest, J.E., Duncan, A.M., Barriga, F.J.A.S., Chester, D.K. (Eds.), Volcanic Geology of São Miguel Island (Azores Archipelago), Geological Society of London Memoir. vol. 44:pp. 15-32. https://doi.org/10.1144/M44.3.

Manzella, A., Volpi, G., Zaja, A., Meju, M., 2004. Combined TEM-MT investigation of shallow-depth resistivity structure of Mt Somma-Vesuvius. J. Volcanol. Geotherm. Res. 131:19-32. https://doi.org/10.1016/S0377-0273(03)00313-5.

McMurtry, G.M., Fan, P.-F., Coplen, T.B., 1977. Chemical and isotopic investigations of Igroundwater in potential geothermal areas in Hawaii. Am. J. Sci. 277, 438-458.

Montesinos, F.G., Camacho, A.G., Vieira, R., 1999. Analysis of gravimetric anomalies in Furnas caldera (São. Miguel, Azores). J. Volcanol. Geotherm. Res. 92, 67-81.

Moore, R., 1990. Volcanic geology and eruption frequency, São Miguel, Azores. Bull. Volcanol. 52, 602-614.

Morozov, V.A., Stessin, M., 1993. Regularization Methods for Ill-Posed Problems. CRC Press, Boca Raton, FL, p. 257.

Müller, K., Vanderborght, J., Englert, A., Kemna, A., Huisman, J.A., Rings, J., Vereecken, H., 2010. Imaging and characterization of solute transport during two tracer tests in a shallow aquifer using electrical resistivity tomography and multilevel groundwater samplers. Water Resour. Res. 46:W03502. https://doi.org/10.1029/2008WR007595.

Naudet, V., Revil, A., Rizzo, E., Bottero, J.Y., Bégassat, P., 2004. Groundwater redox conditions and conductivity in a contaminant plume from geoelectrical investigations. HESS 8 (1), 8-22.

Nicollin, F., Gibert, D., Beauducel, F., Boudon, G., Komorowski, J.-C., 2006. Electrical tomography of La Soufrière of Guadeloupe volcano: field experiments, 1D inversion and qualitative interpretation. Earth Planet. Sci. Lett. 244, 709-724.

Nocedal, J., Wright, S.J., 2006. Numerical Optimization, Springer Series in Operations Research and Financial Engineering. 2nd Edition.

Orr, T.R., Thelen, W.A., Patrick, M.R., Swanson, D.A., Wilson, D.C., 2013. Explosive eruptions triggered by rockfalls at Kīlauea volcano, Hawai'i'i. Geology 41 (2):207-210. https://doi.org/10.1130/G33564.1.

Oyeyemi, K.D., Olofinnade, O.M., 2016. Geoelectrical-geotechnical studies for near surface characterization, case history: Lagos, SW Nigeria. EJGE 21, 3735-3750.

Pasquet, S., Holbrook, W.S., Carr, B.J., Sims, K.W.W., 2016. Geophysical imaging of shallow degassing in a Yellowstone hydrothermal system. Geophys. Res. Lett. 43. https://doi. org/10.1002/2016GL071306.

Patrick, M.R., Witzke, C.N., 2011. Thermal mapping of Hawai'iian volcanoes with ASTER satellite data. US Geol. Surv. Sci. Investig. Rep. 2011-5110, 22.

Poland, M.P., Carbone, D., 2016. Insights into shallow magmatic processes at Kīlauea volcano, Hawai'i'i, from a multiyear continuous gravity time series. J. Geophys. Res. 121: 5477-5492. https://doi.org/10.1002/2016JB013057.

Pommier, A., Gaillard, F., Malki, M., Pichavant, M., 2010. Re-evaluation of the electrical conductivity of silicate melts. Am. Mineral. 95, 284-291.

Pommier, A., Gaillard, F., Pichavant, M., 2010. Time-dependent changes of the electrical conductivity of basaltic melts with redox state. Geochim. Cosmochim. Acta https:// doi.org/10.1016/j.gca.2009.12.005.

Pommier, A., Gaillard, F., Pichavant, M., Scaillet, B., 2008. Laboratory measurements of electrical conductivities of hydrous and dry mount Vesuvius melts under pressure. J. Geophys. Res. 113:B05205. https://doi.org/10.1029/2007JB005269.

Pommier, A., Le-Trong, E., 2011. "SIGMELTS": a web portal for electrical conductivity calculations in geosciences. Comput. Geosci. 37, 1450-1459.

Reid, M.E., Sisson, T.W., Brien, D.L., 2001. Volcano collapse promoted by hydrothermal alteration and edifice shape, Mount Rainier, Washington. Geology 29, 779-782.

Revil, A., Cathles, L.M., Losh, S., Nunn, J.A, 1998. Electrical conductivity in shaly sands with geophysical applications. J. Geophys. Res. 103 (B10) 925-23,936.

Revil, A., 2013. Effective conductivity and permittivity of unsaturated porous materials in the frequency range $1 \mathrm{mHz}-1 \mathrm{GHz}$. Water Resour. Res. 49:306-327. https://doi.org/ 10.1029/2012WR012700.

Revil, A., Darot, M., Pezard, P.A., Becker, K., 1996. Electrical conduction in oceanic dikes, Hole 504B. Ed. by. et al. In: Alt, J.C., Kinoshita, H. (Eds.), Proc. ODP Sci. Res., 148, College Station, TX (ODP), pp. 297-305.

Revil, A., Eppehimer, J.D., Skold, M., Karaoulis, M., Godinez, L., Prasad, M., 2013. Low-frequency complex conductivity of sandy and clayey materials. J. Colloid Interface Sci. 398:193-209. https://doi.org/10.1029/2010GL043983.

Revil, A., Hermitte, D., Spangenberg, E., Cochémé, J.J., 2002. Electrical properties of zeolitized volcaniclastic materials. J. Geophys. Res. 107 (B8):2168. https://doi.org/ 10.1029/2001JB000599.

Revil, A., Johnson, T.C., Finizola, A., 2010. Three-dimensional resistivity tomography of Vulcan's forge, Vulcano Island, southern Italy. Geophys. Res. Lett. 37 (15).

Revil, A., Le Breton, M., Niu, Q., Wallin, E., Haskins, E., Thomas, D.M., 2017. Induced polarization of volcanic rocks. 1 . Surface versus quadrature conductivity. Geophys. J. Int 208:826-844. https://doi.org/10.1093/gii/ggw444.

Revil, A., Murugesu, M., Prasad, M., Le Breton, M., 2017. Alteration of volcanic rocks: a new non-intrusive indicator based on induced polarization measurements. J. Volcanol Geotherm. Res. 341:351-362. https://doi.org/10.1016/j.jvolgeores.2017.06.016.

Rinaldi, A.P., Todesco, M., Vandemeulebrouck, J., Revil, A., Bonafede, M., 2011. Electrical conductivity, ground displacement, gravity changes, and gas flow at Solfatara crater (Campi Flegrei caldera, Italy): results from numerical modeling. J. Volcanol. Geotherm. Res. 207, 93-105.

Rosas-Carbajal, M., Komorowski, J.C., Nicollin, F., Gibert, D., 2016. Volcano electrical tomography unveils edifice collapse hazard linked to hydrothermal system structure and dynamics. Sci. Rep. 6 (29899). https://doi.org/10.1038/srep29899.

Ruffet, C., Gueguen, Y., Darot, M., 1991. Complex conductivity measurements and fractal nature of porosity. Geophysics 56 (6):758-768. https://doi.org/10.1190/1.1443093. 
Satherley, J., Smedley, S.I., 1985. The electrical conductivity of some hydrous and anhydrous molten silicates as a function of temperature and pressure. Geochim. Cosmochim. Acta 49, 769-777.

Schwarzbach, C., Haber, E., 2013. Finite element based inversion for time-harmonic electromagnetic problems. Geophys. J. Int. 193 (2):615-634. https://doi.org/10.1093/gji/ ggt006.

Searle, R., 1980. Tectonic pattern of the Azores spreading centre and triple junction. Earth Planet. Sci. Lett. 51, 415-434.

Sen, P.N., Scala, C., Cohen, M.H., 1981. A self-similar model for sedimentary rocks with application to the dielectric constant of fused glass beads. Geophysics 46, 781-795.

Shainberg, I., Levy, R., 1975. Electrical conductivity of Na-montmorillonite suspensions. Clay Clay Miner. 23, 205-210.

Silva, C., Viveiros, F., Ferreira, T., Gaspar, J.L., Allard, P., 2015. Diffuse soil emanations of radon and hazard implications at Furnas Volcano, São Miguel Island (Azores). In Gaspar, J.L., Guest, J.E., Duncan, A.M., Barriga, F.J.A.S., Chester, D.K. (Eds.), Volcanic Geology of S. Miguel Island (Azores archipelago). Geological Society, London, Memoirs vol. 44:pp. 197-211. https://doi.org/10.1144/M44.15.

Storz, H., Storz, W., Javobs, F., 2000. Electrical resistivity tomography to investigate geological structures of the earth's upper crust. Geophys. Prospect. 48, 455-471.

Sudha, K., Israil, M., Mittal, S., Rai, J., 2009. Soil characterization using electrical resistivity tomography and geotechnical investigations. J. Appl. Geophys. 67 (1):74-79. https:// doi.org/10.1016/j.jappgeo.2008.09.012.

Swanson, D.A., Rose, T.R., Fiske, R.S., McGeehin, J.P., 2012. Keanakāko'i Tephra produced by 300 years of explosive eruptions following collapse of Kỉlauea's caldera in about 1500 CE. J. Volcanol. Geotherm. Res. 215-216:8-25. https://doi.org/10.1016/j. jvolgeores.2011.11.009.

Swanson, D.A., Rose, T.R., Mucek, A.E., Garcia, M.O., Fiske, R.S., Mastin, G.L., 2014. Cycles of explosive and effusive eruptions at Kīlauea Volcano, Hawai'i. Geology 42 (7):631-634 July 2014. Data Repository item 2014233. https://doi.org/10.1130/G35701.1.

Tikhonov, A.N., Arsenin, V.Y., 1977. Solutions of Ill-Posed Problems. John Wiley \& Sons, Washington https://doi.org/10.1137/1021044.

Tilling, R.I., Jones, B.F., 1991. Composition of Waters From the Research Drill Hole at Summit of Kilauea Volcano and of Selected Thermal and Non-Thermal Groundwaters, Hawaii, Open-File Report 91-133-A. p. 27.

Troiano, A., Di Giuseppe, M.G., Petrillo, Z., Patella, D., 2009. Imaging 2D structures by the CSAMT method: application to the Pantano di S. Gregorio Magno faulted basin (Southern Italy). J. Geophys. Eng. 6:120-130. https://doi.org/10.1088/1742-2132/6/ $2 / 003$.

Tyburczy, J.A., Waff, H.S., 1983. Electrical conductivity of molten basalt and andesite to 25 kilobars pressure: geophysical significance and implications for charge transport and melt structure. J. Geophys. Res. 88 (B3):2413-2430. https://doi.org/10.1029/ JB088iB03p02413.
Tyburczy, J.A., Waff, H.S., 1985. High pressure electrical conductivity in naturally occurring silicate liquids. In: Shock, R.N. (Ed.), Point Defects in Minerals. Geophysical Monograph Series vol. 31. AGU, Washington, DC, pp. 78-87.

Usui, Y., Ogawa, Y., Aizawa, K., Hashimoto, T., Koyama, T., Kagiyama, T., 2016. Three-dimensional resistivity structure of Asama Volcano revealed by data-space magnetotelluric inversion using unstructured tetrahedral elements. Geophys. J. Int. 208 (3):1359-1372. https://doi.org/10.1093/gji/ggw459.

Vinegar, H.J., Waxman, M.H., 1984. Induced polarization of shaly sands. Geophysics 49: 1267-1287. https://doi.org/10.1190/1.1441755.

Viveiros, F., Cardellini, C., Ferreira, T., Caliro, S., Chiodini, G., Silva, C., 2010. Soil $\mathrm{CO}_{2}$ emissions at Furnas volcano, São Miguel Island, Azores archipelago: volcano monitoring perspectives, geomorphologic studies, and land use planning application. J. Geophys. Res. 115:B12208. https://doi.org/10.1029/2010JB007555.

Wahba, G., Wang, Y., 1995. Behavior near zero of the distribution of GCV smoothing parameter estimates. Statistics \& Probability Letters 25 (2):105-111. https://doi.org/ 10.1016/0167-7152(94)00211-P.

Wang, D., Mookherjee, M., Xu, Y., Karato, S.-I., 2006. The effect of water on the electrical conductivity of olivine. Nature 443. https://doi.org/10.1038/nature05256.

White, D.E., Fournier, R.O., Muffler, J.P., Truesdell, A.H., 1975. Physical results of research drilling in thermal areas of Yellowstone National Park, Wyoming. U. S. Geol. Surv. Prof. Pap.:892. https://pubs.er.usgs.gov/publication/pp892.

White, D.E., Muffler, L.J.P., Truesdell, A.H., 1971. Vapor-dominated hydrothermal systems compared with hot-water systems. Econ. Geol. 66 (1), 75-97.

Winsauer, W.O., Shearing, H.M., Masson, P.H., Williams, M., 1952. Resistivity of brine saturated sands in relation to pore geometry. AAPG Bull. 36 (2):253-277. https://doi. org/10.1306/3d9343f4-16b1-11d7-8645000102c1865d.

Wolfe, E.W., Morris, J., 1996. Sample Data for the Geologic Map of the Island of Hawai'ii: U. S. Geological Survey Miscellaneous Investigations Series Map I-2524-B, Scale 1: 100,000. p. 51.

Wooten, K.M., Thornber, C.R., Orr, T.R., Ellis, J.F., Trusdell, F.A., 2009. Catalog of tephra samples from Kīlauea's summit eruption, March-December 2008. U.S. Geol. Surv. Open File Rep. 2009, 1134.

Yoshino, T., Manthilake, G., Matsuzaki, T., Katsura, T., 2008. Dry mantle transition zone inferred from electrical conductivity of wadsleyite and ringwoodite. Nature 451, 326-329.

Zandomeneghi, D., Almendros, J., Ibáñez, J.M., Saccorotti, G., 2008. Seismic tomography of Central São Miguel, Azores. Phys. Earth Planet. Inter. 167, 8-18.

Zhou, J., Revil, A., Karaoulis, M., Hale, D., Doetsch, J., Cuttler, S., 2014. Image-guided inversion of electrical resistivity data. Geophys. J. Int. 197:292-309. https://doi.org/ $10.1093 / \mathrm{gii} / \mathrm{ggu} 001$. 